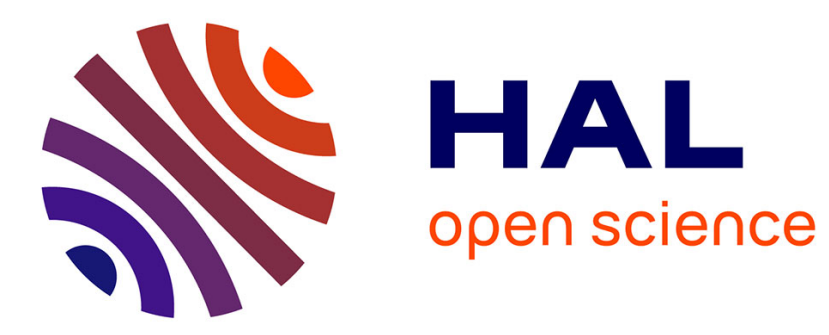

\title{
Ultra-rapid axon-axon ephaptic inhibition of cerebellar Purkinje cells by the pinceau
}

\author{
Antonin Blot, Boris Barbour
}

\section{To cite this version:}

Antonin Blot, Boris Barbour. Ultra-rapid axon-axon ephaptic inhibition of cerebellar Purkinje cells by the pinceau. Nature Neuroscience, 2014, 17 (2), pp.289-295. 10.1038/nn.3624 . hal-02413640

\author{
HAL Id: hal-02413640 \\ https://hal.science/hal-02413640
}

Submitted on 16 Dec 2019

HAL is a multi-disciplinary open access archive for the deposit and dissemination of scientific research documents, whether they are published or not. The documents may come from teaching and research institutions in France or abroad, or from public or private research centers.
L'archive ouverte pluridisciplinaire HAL, est destinée au dépôt et à la diffusion de documents scientifiques de niveau recherche, publiés ou non, émanant des établissements d'enseignement et de recherche français ou étrangers, des laboratoires publics ou privés. 


\title{
Ultra-rapid axon-axon ephaptic inhibition of cerebellar Purkinje cells by the pinceau
}

\author{
Antonin Blot \& Boris Barbour \\ Ecole Normale Supérieure, IBENS, Paris, F-75005, France. \\ CNRS, UMR 8197, Paris, F-75005, France. \\ INSERM, U 1024, Paris, F-75005, France. \\ Correspondance: boris.barbour@ens.fr
}

Running title: Cerebellar pinceau

December 6, 2013 


\begin{abstract}
Excitatory synaptic activity in the brain is shaped and balanced by inhibition. Because inhibition cannot propagate, it is often recruited with a synaptic delay by incoming excitation. Cerebellar Purkinje cells are driven by long-range excitatory parallel fibre inputs, which also recruit local inhibitory basket cells. The axon initial segment of each Purkinje cell is ensheathed by basket cell axons in a structure called the pinceau, which is largely devoid of chemical synapses. Here we show at the single-cell level in mice that the pinceau mediates ephaptic inhibition of Purkinje cell firing at the site of spike initiation. The reduction of firing rate is synchronous with the presynaptic action potential, eliminating a synaptic delay and allowing granule cells to inhibit Purkinje cells without a preceding phase of excitation. This constitutes the fastest intercellular inhibitory mechanism reported in the brain, implementing ultra-rapid feedforward and lateral inhibition.
\end{abstract}

Inhibition is essential to normal brain function. Most obviously, it prevents the runaway positive feedback that would result if neurones were interconnected by excitation alone. However, the large number of classes of inhibitory interneurones are thought to play a variety of other roles, notably in the genesis of oscillations. Several inhibitory circuit topologies have been described, such as feedforward and feedback inhibition, conferring different timescales and conditions of recruitment. Inhibition can also target different neuronal regions, with dendritic inhibition contributing to synaptic integration and somatic or axonal inhibition regulating the timing of action potential emission. In contrast to excitation, inhibition is unable to propagate from neurone to neurone in any direct manner. As a consequence, long-range inputs to a brain region are usually excitatory and local inhibition is then recruited with a delay by excitation of interneurones.

The cerebellum contributes to the learning and control of coordinated movements ${ }^{1}$. In the cerebellar cortex, the sole output neurones, the GABAergic Purkinje cells, receive inhibitory inputs from basket cells ${ }^{2}$ (diagram in Supplementary Fig. 1a; other interneurones are not shown). Both types of cell are driven by the excitatory granule cells. Axon terminals from multiple basket cells enlace Purkinje cell somata, forming 'baskets' containing chemical synapses (Supplementary Fig. 1b), and then extend to wrap around the initial segment of the Purkinje cell axon in a structure called the pinceau ${ }^{2}$, which is largely devoid of chemical and electrical synapses ${ }^{3-5}$. The basket cell axons are linked by septate junctions ${ }^{3}$, potentially creating 
a partially isolated compartment. On the basis of classical studies of the Mauthner cell axon cap ${ }^{6,7}$, a possibly analogous though much larger structure in fish, it has been conjectured ${ }^{3,8,9}$ that the cerebellar pinceau mediates ephaptic ${ }^{10-12}$ inhibition via the electrical field surrounding the Purkinje cell axon initial segment.

We set out to test this hypothesis. Our starting point was a previous paper ${ }^{13}$ that attempted to study the pinceau using very intense stimulation of parallel fibre bundles to excite basket cells indirectly, while recording from Purkinje cells. When we tried a similar approach, we discovered that the signals recorded in the Purkinje cell were generated by the parallel fibre volley and not by the pinceau. Further analysis showed that all of the results of that paper could, unfortunately, be explained by this artefact. A more detailed exposition of these issues is available ${ }^{14}$.

As nothing was therefore known about the operation of the pinceau, beyond the potential analogy with the fish axon cap, we started afresh using whole-cell recording to control individual basket cells. By resolving at the pinceau signals orders of magnitude smaller than those found in the fish axon cap, we were able to demonstrate, at the single-cell level, the existence of an extremely rapid ephaptic mechanism. We elucidated the electrical processes underlying this transmission, finding that the major component of this transmission occurred via a novel capacitive mechanism. Modelling the operation of the pinceau allowed us to deduce that intracellular voltages or currents produced by the pinceau would be undetectable using standard recording techniques. Finally, we show how this ultra-rapid inhibitory mechanism enables fast, bidirectional modulation of cerebellar cortical output.

\section{Results}

\section{Non-synaptic inhibition of Purkinje cell activity}

In order to study the action of the pinceau, we established whole-cell recordings of basket cells in sagittal slices of cerebella from adult mice (Methods). The interneurone was filled with a fluorophore via the patch pipette (Fig. 1a), allowing online targeting and offline identification of Purkinje cells innervated by the recorded basket cell via the pinceau (Fig. 1b,c; Methods).

Purkinje cells were recorded extracellularly. For cell pairs classified as involving a pinceau $(n=14)$, an action potential in the basket cell (Fig. 1d and h) reduced Purkinje cell firing (Fig. 1e) over a few milliseconds, as evidenced by the cross-correlogram (Fig. 1f and $\mathbf{j}$ ). We blocked 
GABAergic transmission in these Purkinje cells using gabazine $(5 \mu \mathrm{M})$, revealing a biphasic modulation of firing exceeding 3 standard deviations of the baseline in 12/14 cells (Fig. $\mathbf{1 g}$ and $\mathbf{l}$ ). This comprised an initial inhibition of $9.1 \pm 1.5 \mathrm{~Hz}$, with a full-width at half-maximum (FWHM) of $0.9 \pm 0.05 \mathrm{~ms}$ (measured on a smoothed correlogram), followed by an excitation of $7.0 \pm 1.9 \mathrm{~Hz}$ (FWHM $1.4 \pm 0.1 \mathrm{~ms}$ ) that would, however, normally be obscured by the chemical inhibition, ensuring uninterrupted inhibition. The trough-to-peak time was $1.6 \pm 0.2 \mathrm{~ms}$. With respect to the peak of the basket cell action potential, the inhibition reached $20 \%$ of peak $0.4 \pm 0.1 \mathrm{~ms}$ before, and was maximal $0.4 \pm 0.03 \mathrm{~ms}$ after. Both inhibitory and excitatory phases were significantly different from the baseline firing rate $(p=0.00012$ for inhibition, $p=0.00012$ for excitation; comparisons of $1 \mathrm{~ms}$ bins with $10 \mathrm{~ms}$ of baseline, $n=14$, paired Wilcoxon test). We shall show below that this modulation of firing reflects the ephaptic action of the pinceau.

Subtraction of the cross-correlograms in the presence and absence of gabazine revealed the amplitude $(23.2 \pm 4.3 \mathrm{~Hz})$ and timing of the matched chemical inhibition (Fig. 1n), whose onset (20\%) occurred $0.5 \pm 0.3 \mathrm{~ms}$ after the peak of the basket cell somatic action potential. The gabazine-resistant inhibition therefore started $0.9 \mathrm{~ms}$ before the associated chemical inhibition. Maximal chemical inhibition was attained $1.7 \pm 0.4 \mathrm{~ms}$ after the basket cell action potential peak and $1.3 \pm 0.2 \mathrm{~ms}$ after the peak of the gabazine-resistant response.

We note that our recordings made use of a calcium concentration somewhat higher than that in vivo $(2 \mathrm{mM} \text { vs } \leq 1.5 \mathrm{mM})^{15}$, enabling better detection and measurement of the chemical inhibitory component. This implies, however, that the strength of the chemical inhibition was probably overestimated and the relative importance of the putative electrical inhibition therefore underestimated.

The short duration of the chemical inhibitory effect may appear surprising; it arises from a combination of factors: the small amplitude of interneurone-Purkinje cell connections in the adult ${ }^{16,17}$, the rapid decay of somatic inputs in adult Purkinje cells at physiological temperature ${ }^{17}$ and shunting of somatic inputs by the dendritic compartment. The slight overshoot of firing after the chemical inhibition (Fig. $\mathbf{1 j}, \mathbf{n})$ may reflect the somatic voltage 'catching up' the dendritic voltage, which continues to depolarise during the inhibition, transiently increasing the firing rate above the baseline value.

Anatomical studies suggest that only a minority of axon branches contacting the soma do not continue into the pinceau ${ }^{2,18,19}$; one report ${ }^{20}$ evaluates the proportion as $19 \%$. Furthermore, non-pinceau connections tend 
to occur at the baskets furthest from the interneurone soma ${ }^{21}$. To provide a control group, we targeted recordings to this minority arrangement of Purkinje cell somata approached by basket cell axons that did not contribute to the pinceau. In $9 / 22$ of these cells, the action potential in the basket cell induced an inhibition (Fig. 1i, k): amplitude $24.4 \pm 1.4 \mathrm{~Hz}, 20 \%$ onset $0.9 \pm 0.2 \mathrm{~ms}$, FWHM $2.5 \pm 0.3 \mathrm{~ms}$. This was abolished in $8 / 9$ cells by application of gabazine (Fig. 1 $\mathbf{m}$ ), indicating the presence of a chemical synapse only.

Although our classification of pinceau connections, based upon vital fluorescence and transmitted light images, apparently displayed small falsepositive and false-negative rates (Methods), the early gabazine-resistant inhibition was significantly different between the 'pinceau' and 'non-pinceau' groups ( $p=0.0005$; Wilcoxon test; $n=14$ and $n=9$, respectively). We conclude that a gabazine-resistant biphasic modulation of Purkinje cell firing rate was associated with the presence of the recorded basket cell's axon in the pinceau.

\section{Extracellular voltage field at the pinceau}

It has recently been confirmed that action potential initiation in the Purkinje cell occurs at the axon initial segment ${ }^{22}$, which is precisely the part of the axon ensheathed by the pinceau. Morphological and histological studies have provided no evidence for any gap junctions between basket cell and Purkinje cell axons in the pinceau ${ }^{3-5}$, suggesting that the effect may occur via modulation of the extracellular voltage between the two cells ${ }^{7}$. A reduction of firing rate implies a membrane hyperpolarisation at the point of initiation, which, we shall show below, requires an extracellular positivity. Because the extracellular field produced by an action potential would normally be dominated by the sodium-current-induced negativity, we next investigated the extracellular potentials associated with basket cell action potentials at the pinceau and elsewhere.

We recorded the extracellular potential at multiple sites near different basket cell elements (Fig. 2a, b), triggered on the basket cell action potential. A variety of waveforms were observed, with juxta-somatic and most juxta-axonal sites displaying the expected negativity (Fig. 2c). In contrast, close to the pinceau, only a positivity was observed, which in some cases appeared to be composed of two components (e.g. traces 11 and 12 in Fig. 2c). A positivity was observed in recordings from 10/11 pinceaux from 6 basket cells (Fig. 2d). On average, the positivity was $15.6 \pm 2.5 \mu \mathrm{V}(n=11)$ in amplitude with a FWHM of $1.49 \pm 0.24 \mathrm{~ms}$. The onset of the extracellu- 
lar waveform ( $20 \%$ of peak) occurred $0.16 \pm 0.08 \mathrm{~ms}$ before the peak of the somatic action potential in the basket cell.

\section{Two components of the pinceau field}

We next sought to understand the processes by which the extracellular field was generated. The previous work on the fish axon cap ${ }^{6,7,23,24}$ did not suggest any detailed mechanism. The absence of a negative component in the extracellular field recorded near the pinceau suggested that the axon terminals they contained were devoid of sodium channels. In the absence of sodium channels, the action potential would propagate electrotonically the short distance from the active axon in the basket to the pinceau. Two current components would be expected: an outward (then inward) capacitive current resulting from local circuit currents and an outward ionic current through voltage-activated potassium conductances, several of which are expressed in the pinceau ${ }^{4,25-29}$. Consistently with this hypothesis, in cells where the application of $100 \mathrm{nM} \alpha$-dendrotoxin ( $\alpha$-DTX), a potent blocker of Kv1.1 and Kv1.2 channels $^{30}$ changed only modestly the spike shape at the soma (Fig. 3a,c,e), the first peak of the extracellular depolarisation was also little altered (Fig. 3b,d,f, $23.4 \pm 5.2 \mu \mathrm{V}$ in control, $21.7 \pm 4.4 \mu \mathrm{V}$ in $\alpha$-DTX, $p=0.36$, Wilcoxon test, $n=9)$, but the second peak was reduced by $43 \pm 9 \%(21.6 \pm 4.9 \mu \mathrm{V}$ in control, $11.7 \pm 3.1 \mu \mathrm{V}$ in $\alpha$-DTX, $p=0.008$, Wilcoxon test, $n=9$ ). The timing of the first component of the extracellular field was consistent with a capacitive mechanism, while the sensitivity of the second to $\alpha$-DTX showed that it was mediated by a potassium conductance. Similar electrotonic propagation has been described in other axon terminals ${ }^{31}$. The existence of the capacitive component is of potential significance, because it precedes the potassium conductance, thereby enabling the fastest possible pinceau action.

\section{Pinceau mechanism}

How does the extracellular positivity affect Purkinje cell firing? In models of the Mauthner's cell axon cap ${ }^{6,23,24}$ the extracellular positivity is transferred to the inside of the Purkinje cell via a resistive mechanism. This is unlikely to be correct, at least at the pinceau, because at the characteristic frequency of action potential-related signals (such as the extracellular field they generate), the admittance of typical resting neuronal membrane will be dominated by the capacitance rather than the conductance. Thus, the admittance at $500 \mathrm{~Hz}$ of the membrane capacitance will be $2 \pi f C=2.4 \mathrm{mS} \mathrm{cm}^{-2}$, com- 
pared to a specific membrane conductance of $8.1 \mu \mathrm{S} \mathrm{cm}^{-2}$ (using the value for Purkinje cells ${ }^{32}$ ). Most of the current flow into the axon should therefore occur via the membrane capacitance, rather than via the resistance as suggested. (The capacitive current would return via the somato-dendritic compartment.) We note moreover that the resistance of the axon may be even higher than we assume, given the apparent absence of potassium channels from the initial segment ${ }^{5,33}$.

To gain further insight into the pinceau mechanism, we modelled an equivalent electrical circuit of the pinceau incorporating capacitive coupling to the Purkinje cell axon (Fig. 4a-f and Methods). The model reproduced the essential features of both the juxta-pinceau potential (Fig. 4c) and firing modulation (Fig. $\mathbf{4 g}, \mathbf{h}$ ). Thus, an extracellular positivity was generated via capacitive and ionic components, as demonstrated by setting the potassium conductance to zero or the capacitance of the basket axon to a negligible value (Fig. 4f). The temporal separation of the two components was modest, as in the experiments (Figs. 2d and $\mathbf{3 b}$ ). The effect of the pinceau on Purkinje cell firing (Fig. $\mathbf{4 h}$ ) was biphasic, with an initial inhibition, as observed experimentally (Fig. 11). Compared to the experimental data, the excitatory rebound of the firing appears somewhat larger in this modelling. This may reflect the fact that the modulation of firing depends on the 'action potential' waveform in the pinceau. Thus, slowing its repolarisation phase by $50 \%$ reduced the rebound (Fig. $\mathbf{4 g}$ ). The precise voltage time courses in the basket and pinceau are not known, but in our extracellular recordings around the tangential axon, the action potential displayed a broad negativity indicating that it is indeed likely to be broader than at the soma (trace 6 vs 0 on Fig. 2c).

The location of the pinceau at the Purkinje cell spike initiation zone ${ }^{22}$ and the tiny capacitance of the initial segment $(<1 \mathrm{pF})$ underlie the sensitivity and rapidity of this inhibitory mechanism. Interestingly, relative to a distant voltage reference, the overwhelming contribution to the variations of axonal membrane potential is from the local extracellular potential $\left(V_{P}\right.$; Fig. 4c); the intracellular somatic voltage responses $\left(V_{S}\right)$ would be negligibly small in a standard recording $(\sim 1 \mu \mathrm{V} ; \mathbf{F i g} .4 \mathbf{4 d})$. This was one of the reasons that obliged us to demonstrate the pinceau effect through its modulation of the Purkinje cell firing rate (Fig. 1).

The model offers insight into how the serial-capacitive transmission advances the onset of the inhibition. The initial phase of the membrane current flowing out of the basket cell axon is capacitive (Fig. 4f) and is therefore approximately proportional to $d V_{B A} / d t$; this current sets the intra-pinceau potential $V_{P}$ (Fig. 4c). When Purkinje cells are spontaneously active ('pace- 
making'), their average firing rate is, to a first approximation, proportional to the derivative of the axonal membrane potential $d\left(V_{P A}-V_{P}\right) / d t$, since this describes the rate at which Purkinje cells cross threshold. In other words, a reduction of this derivative by the pinceau will reduce the firing rate. Given that $V_{P A}$ is barely altered by the pinceau, the pinceau-induced variations of axonal transmembrane potential are to an excellent approximation $-V_{P}\left(\right.$ Fig. 4c), so the inhibitory effect is proportional to $-d V_{P} / d t$. The rapid onset of the inhibition of the Purkinje cell is therefore related to the second derivative of the basket cell action potential, which peaks early in the waveform.

In the supplementary information we provide an analysis showing why a basket cell action potential in the 'basket' - the axon apposed to the Purkinje cell soma - is not expected to inhibit Purkinje cell firing nearly as strongly as the pinceau, despite larger somatic intracellular signals being induced (Supplementary Fig. 2).

\section{Juxta-axonal fields mimic the pinceau effect}

Our modelling of the pinceau mechanism suggested that localised electrical fields at the initial segment are sufficient to modulate Purkinje cell firing. We set out to test this prediction directly by producing local alterations of the extracellular potential and measuring their effect on Purkinje cell activity.

We changed the extracellular voltage by passing current through a salinefilled patch electrode positioned within the presumed location of the pinceau (Methods). To control the voltage drop across the pipette resistance, we measured the extracellular field at the electrode tip using another electrode connected to one of our home-built extracellular amplifiers (Methods). The stimulus intensity was adjusted to yield initially an extracellular field of similar amplitude to that our modelling predicted for the pinceau interior (about $200 \mu \mathrm{V}$ ). A second electrode recorded the extracellular potential at the Purkinje cell soma. Spikes were recorded on either of the two extracellular electrodes. In the control configuration, the stimulating electrode was placed at the somatic recording electrode.

We first produced positive and negative step changes of the juxta-axonal voltage of $3 \mathrm{~ms}$ duration; we also applied a longer step of $6 \mathrm{~ms}$ (Fig. 5a). These steps modulated Purkinje cell firing (Fig. 5e). The signs and amplitudes of the changes were consistent with our modelling predictions. Thus, a $3 \mathrm{~ms}$ positive extracellular potential of $239 \pm 24 \mu \mathrm{V}$ reduced firing by $20.5 \pm 2.7 \mathrm{~Hz}$, while a negative step produced an almost symmetrical in- 
crease of firing of $21.1 \pm 4.8 \mathrm{~Hz}(n=21)$. At the ends of the steps, firing modulations of opposite sign were produced. This suggested that the firing modulation was related to the derivative of the extracellular voltage, as predicted by our modelling above. The longer voltage step confirmed this by demonstrating clearly that the modulation of firing was transient, the rate returning to baseline during the step. The amplitude of the firing modulation with $3 \mathrm{~ms}$ steps was correlated with that of the extracellular voltage at the axon (Fig. 5g, $\Delta$ firing $(\mathrm{Hz})=-70.2 \mathrm{~V}_{\text {axon }}(\mathrm{mV})+1.2, p<0.0001$, $F(1,54)=117.1)$.

Our modelling suggested that extracellular voltage changes at the soma should be less effective than those at the axon (Supplementary Fig. 2). We tested this by applying the same stimulus close to the soma (Fig. $\mathbf{5 b} \mathbf{b}, \mathbf{d , f}$ ). Although a somewhat larger voltage was produced $(361 \pm 60 \mu \mathrm{V}$; presumably because the soma occludes part of the extracellular space), the somatic stimulation produced only a small modulation of firing $(5 \pm 2 \mathrm{~Hz}$, $n=14)$. The difference with the response to axonal stimulation was significant $(p=0.0006$, paired wilcoxon test, $n=14)$. Moreover, measurement of the juxta-axonal voltage during somatic stimulation suggested that it was largely responsible for this residual modulation. Accordingly, the amplitude of the firing modulation was not correlated with the juxta-somatic voltage changes $(p=0.13, F(1,20)=2.5)$ but was with the juxta-axonal changes $\left(\Delta\right.$ firing $\left.(\mathrm{Hz})=-101.5 \mathrm{~V}_{\text {axon }}(\mathrm{mV})+0.4, p=0.0004, F(1,20)=18.3\right)$.

Finally, we applied a scaled version of the average extracellular voltage waveform measured at the pinceau (Fig. 5h). This waveform, with an amplitude of $\sim 300 \mu \mathrm{V}$, produced a biphasic modulation similar in shape to that produced by the pinceau (Fig. 5i). The inhibition produced by the direct stimulation had the following properties (times were referred to the peak of the basket cell action potential of the original field recordings; $n=8$ ): peak response (bin $0.5-1 \mathrm{~ms})-20 \pm 2.5 \mathrm{~Hz}$; peak time $0.83 \pm 0.04 \mathrm{~ms}$; FWHM $1.06 \pm 0.05 \mathrm{~ms}$. The succeeding excitatory rebound peaked at $2.51 \pm$ $0.08 \mathrm{~ms}$ and produced a modulation of $21.2 \pm 2.6 \mathrm{~Hz}$ (bin $2-3 \mathrm{~ms}$ ). The inhibition was larger than that observed in Fig. 11, suggesting that the intra-pinceau potential is significantly smaller that the $300 \mu \mathrm{V}$ applied here, thus corresponding quite closely to the magnitude of about $200 \mu \mathrm{V}$ predicted in our modelling (see Fig. 4c,f and text).

The kinetics of the modulation induced by the applied field were somewhat slower than those observed with physiological pinceau activation. One possible contributing factor could be that the extracellular field produced is more extensive than that generated by and restricted within the pinceau.

These experiments directly link the extracellular field produced by the 
pinceau to the fast inhibition of Purkinje cell firing, as well as providing corroborating evidence for several features of our modelling analysis, notably the relation of firing modulation to the derivative of the extracellular field and the scale of the voltage changes required.

\section{Opposing direct excitation}

In order to predict the effect of pinceau-mediated inhibition during granule cell input that would recruit both basket cells and Purkinje cells, we made dual whole-cell current-clamp recordings in which the basket cell contributed to the basket of the recorded Purkinje cell, ensuring realistic relative timing. We measured spike times simultaneously in both cell types while stimulating parallel fibres (Fig. 6a,b). We analysed recordings where the Purkinje cell firing rate was modulated (peak excitation at least 3 SDs from a 10 ms baseline) but did not exceed $250 \mathrm{~Hz}(n=5$; Fig. 6a), corresponding roughly to the physiological range observed in vivo ${ }^{34}$. Between stimuli, basket cells were maintained quiescent at around $-50 \mathrm{mV}$. To correct for different parallel fibre propagation latencies, we aligned the $20 \%$ rise points of the basket cell responses.

We then used the approach of linear superposition of correlograms ${ }^{35}$, which is a broadly applicable linear approximation whereby complex correlograms resulting from multiple interactions between neurones can be predicted through summation of the elementary correlograms for individual interactions. This method would be exact when applied to the model described in Fig. 4, which was designed to be linear.

We convolved the average modulation of frequency induced by the chemical inhibition alone (Fig. 1n) or the pinceau and the chemical inhibition together (Fig. 1j) with the basket cell spike time probability density function (Fig. 6b) to obtain the stimulus-induced basket cell effects with and without the pinceau (Fig. 6c). Estimates of the number of basket cells contributing to each pinceau vary widely, from 3 to $50^{18,19,36}$. We added 10 times these convolutions to the Purkinje cell response (Fig. 6a), to predict the effect of parallel fibre recruitment of multiple basket cells with or without a pinceau (Fig. 6d). Note that our simplified model becomes invalid if the frequency is reduced to zero, so subsequent rates are represented by dashed lines in the figure. The modelling shows that the peak response of Purkinje cells to parallel fibre input $(135 \pm 23 \mathrm{~Hz})$ would be strongly reduced by basket cells with a pinceau (Fig. 6d; to $84 \pm 26 \mathrm{~Hz}$, a reduction of $52 \pm 6 \mathrm{~Hz}$ ). Basket cells without a pinceau would have a weaker effect on this peak (a reduction of $22 \pm 4 \mathrm{~Hz}$ to $113 \pm 37 \mathrm{~Hz}$ ) and 38 would be required to reduce 
peak excitation to the same level as could 10 basket cells with a pinceau. We recall that the calcium concentration used in our recordings tended to cause underestimation of the relative efficacy of the pinceau compared to the chemical inhibition.

Parallel fibres could therefore rapidly induce a reduction of Purkinje cell firing with no or minimal preceding excitation, by recruiting basket cells making pinceau connections. Basket cells may be synchronised by gap junctions ${ }^{37,38}$ and/or mutual inhibition ${ }^{39,40}$. Such synchrony would enable even stronger effects on Purkinje cell firing, peaking at around $10 \mathrm{~Hz}$ per basket cell.

\section{Discussion}

We have demonstrated for the first time in mammals a single-cell ephaptic mechanism, confirming the conjectures of an anology with the Mauthner cell axon cap ${ }^{3,8,9}$. Compared to the axon cap, where the extracellular potentials near the Mauthner cell axon hillock reach $20 \mathrm{mV}$, our results reveal an unexpectedly subtle mode of action, with potentials some two orders of magnitude smaller $(\sim 200 \mu \mathrm{V}$ in the pinceau) modulating spike initiation directly at the axon initial segment. By directly controlling the extracellular voltage, we showed that it can link the basket cell action potential and the fast inhibition of Purkinje cell firing.

The modelling we performed indicates that naive intracellular recordings would be incapable of resolving the pinceau-specific signals, both because they would be exceedingly small, but also because they would usually be swamped by larger signals resulting from the field generated by the basket axons around the Purkinje cell soma (Supplementary Fig. 2); these confounding signals would however exercise a much smaller effect on spike initiation than the pinceau. These considerations may explain why the only previous attempt to study the physiology of the pinceau ${ }^{13}$ was confused by an unrelated signal arising from parallel fibres ${ }^{14}$. We provide mechanistic information about the processes generating the juxta-axonal ephaptic field. It is composed of both an early capacitive component and a succeeding component mediated by a potassium conductance. The positivity produces a biphasic effect on Purkinje cell firing, with the excitatory phase normally being occluded by the following chemical inhibition.

The inhibitory action of the pinceau is faster than any other described in the nervous system. Although gap junctions can mediate very rapid effects, their initial response to an action potential is excitatory not inhibitory. The 
pinceau effect starts $0.9 \mathrm{~ms}$ before that of chemical inhibition and the interval between the peak effects of these components is $1.3 \mathrm{~ms}$. This is sufficient to eliminate the synaptic delay between incoming excitatory activity and the local inhibition it recruits. As we show in Fig. 6, the ephaptic pinceau effect enables basket cells recruited by parallel fibres to inhibit Purkinje cells simultaneously with the direct excitation, at a time when chemical inhibition is much less effective.

The ability of ephaptic inhibition to compete directly with excitation offers functional benefits to cerebellar operation. Purkinje cells are continuously active in vivo (and spontaneously active in vitro), enabling them to signal to downstream targets - the deep cerebellar nuclei - via both increases and decreases of firing frequency ${ }^{41}$. We consider that these responses are learnt through plasticity of parallel fibre synapses on Purkinje cells, but also on molecular layer interneurones ${ }^{42}$ and possibly plasticity of inhibitory synapses on Purkinje cells ${ }^{43}$. The granule cell input to Purkinje cells is generally considered to be sparsely active ${ }^{44,45}$. An increase of Purkinje cell firing rate can therefore be trivially engendered by an increase of granule cell activity, which will excite Purkinje cells and result in inhibition of neurones in the deep cerebellar nuclei ${ }^{46}$.

In contrast, reduction of Purkinje cell firing is likely to involve recruitment of the stellate and basket cells by granule cells. If these interneurones employed only chemical inhibition, the active parallel fibres would initially excite the Purkinje cell before the feedforward inhibition took effect. Such initial excitation would be counterproductive and destabilising in a situation where an inhibition was required. With the addition of the ephaptic mechanisms, however, granule cell excitation of basket cells could reduce Purkinje cell firing without a preceding phase of excitation, speeding and greatly simplifying downstream signalling. The pinceau therefore enables granule cells to produce a pure inhibition of Purkinje cells. Looked at another way, the pinceau allows the synthesis of granule cell inputs with negative synaptic weights. Although it might be argued that a similar result could be obtained by depressing the active parallel fibre-Purkinje cell synapses to silence $^{47}$, this would represent a significant constraint on learning ${ }^{48,49}$; the pinceau allows pure inhibition to be produced without requiring silencing of all active granule cell-Purkinje cell synapses.

Finally, chandelier (or axo-axonic) cell axons accumulate around the initial segments of principal cells in many brain regions ${ }^{50}$. Although these structures certainly contain chemical synapses, in contrast to the pinceau, the similarities between the pinceau and the plexuses around pyramidal cell initial segments raise the possibility that chandelier cells also regulate 
activity of their target neurones via a hitherto unsuspected rapid ephaptic action. Intriguingly, whereas the pinceau expresses high levels of potassium channels ${ }^{33}$, the axon terminals of the chandelier cells appear to express none (at least not Kv1.1 or Kv1.2) ${ }^{5}$. We hypothesise that this would imply excitatory rather than inhibitory ephaptic signalling. 


\section{Acknowledgements}

This work was supported by the ANR (ANR-08-SYSC-005, ANR-08-BLAN0023) and the ENS (fellowship to A.B.). We thank David Attwell, Marco Beato, Nicolas Brunel, Mariano Casado, Marco Diana, David DiGregorio, Nigel Emptage, Philippe Faure, Anne Feltz, Vincent Hakim, Clément Léna, Troy Margie, Eric Schwartz, Constantino Sotelo, Stéphane Supplisson and Marion Wassef, as well as members of the Barbour group and the IBENS

Neuroscience Section, for helpful discussions and/or critical comments on the manuscript. 


\section{Figure legends}

\section{Figure 1: Non-synaptic inhibition of the Purkinje cell}

(a), Recording configuration. A basket cell (small black dashed circle and arrowhead; soma was saturated and below the focal plane) was patched and filled with Alexa 488 (green). Two Purkinje cells (large black dashed circles) identified as receiving pinceau connections (white arrowheads; the upper pinceau was above the focal plane) from the basket cell were recorded extracellularly. The area in the white dashed box is expanded in (b). (c), Post-fixation confocal projection of the region shown in (b); basket cell (green) and phosphorylated neurofilaments (magenta). Specimen intracellular traces from a basket cell (d) and extracellular traces from a Purkinje cell (e). The horizontal line indicates the spike detection threshold at $-122 \mu \mathrm{V}$. The cross-correlogram (represented by both binned and smoothed histograms) between basket cell $(t=0)$ and Purkinje cell spikes revealed an inhibition in control (f) whose initial component was gabazine-resistant (g). (j)-(o), Smoothed cross-correlograms relative to basket cell spikes (h), (i) (vertical dashed lines) of individual pairs (grey) and their averages (black, all cells; purple, connected cells). Purkinje cells contacted via the pinceau displayed a fast inhibition (j) that was partially gabazine-resistant (l). In basket cell-Purkinje cell pairs with connections only outside the pinceau, the inhibition was slower $(\mathbf{k})$ and abolished by gabazine $(\mathbf{m})$. The difference between control $(\mathbf{j}),(\mathbf{k})$ and gabazine $(\mathbf{l}),(\mathbf{m})$ traces revealed the chemical inhibition (n), (o). Colour bars indicate bins used for baseline (green, partially visible), inhibition (blue) and excitation (yellow) measurements. Scale bars for (a)-(c) $20 \mu \mathrm{m}$. Baseline firing rates were $(\mathrm{Hz})$ : (e), (f) 58; (g), 66; (averages \pm sem) (j), $57 \pm 6 ;(\mathbf{k}), 50 \pm 4 ;(\mathbf{l}), 66 \pm 6 ;(\mathbf{m}), 59 \pm 6$.

\section{Figure 2: Extracellular voltage field at the pinceau}

(a), The extracellular action potential was recorded at multiple sites (circles in the epifluorescence montage) around a basket cell filled with Alexa 488. (b), Diagram of the basket cell, Purkinje cells, slice and recording sites in (a), reconstructed via projection along the vertical axis and classified from epifluorescence and transmitted light images (Methods). (c), A dominant negativity was observed near the soma or tangential axon of the basket cell but a positivity was recorded near the pinceaux. The positivity sometimes displayed two peaks, as in traces 11 and 12 (dashed line: time of peak of the somatic AP). (d), Recordings near basket cell axons in the granule cell 
layer displayed a positivity in 10 out of 11 cases (11 pinceaux from 6 basket cells, grey; black, average).

\section{Figure 3: Two components of the pinceau field}

Somatic action potentials (a, c, e) and extracellular potentials near the pinceaux $(\mathbf{b}, \mathbf{d}, \mathbf{f})$ recorded in basket cells selected for action potential stability before $(\mathbf{a}, \mathbf{b})$ and after application of $100 \mathrm{nM} \alpha$-DTX $(\mathbf{c}, \mathbf{d})$. (e, f), Subtraction of $\alpha$-DTX recordings from controls revealed modest changes of action potential waveform (e) and the Kv1-dependent field component (f). 9 pinceaux from 6 basket cells; grey, individual traces; black, average. Horizontal bars indicate bins used for first (black) and second (grey) peak measurements (Results).

\section{Figure 4: Pinceau model}

(a), Equivalent electrical circuit of the pinceau (Methods). (b)-(f), Potentials and currents induced by a basket cell spike in the absence of Purkinje cell activity. A spike waveform injected in the basket propagated with little decrement to the pinceau (b), inducing a $\sim 200 \mu \mathrm{V}$ positive voltage in the extracellular space between the axons (c) but negligible intracellular voltage changes in the Purkinje cell axon (d). The transmembrane voltage of the Purkinje cell axon was thus hyperpolarised by $\sim 200 \mu$ V. (e), Small currents (inward negative) flowing across the Purkinje cell axon membrane capacitance $C_{P A}$. (Dashed line: peak of the basket cell spike.) (f), Two components of the extracellular positivity (orange). Setting $\overline{G_{K}}=0$ isolated the initial capacitive component (green), while lowering $C_{B A}(/ 100)$ revealed the action of the potassium conductance (purple; dashed line, basket cell action potential). Spike waveforms in the pinceau (g) and corresponding histograms of Purkinje cell spike times (h). Activation of the pinceau by the basket axon action potential waveform in (b) (black) delayed Purkinje cell spikes, reducing the firing rate by $20 \mathrm{~Hz}$ (black traces). Slowing repolarisation (red) of the basket action potential by $50 \%$ selectively reduced the amplitude of the excitatory rebound of firing.

\section{Figure 5: Extracellular voltage clamp}

Small changes of the juxta-axonal voltage modulate Purkinje cell firing. (a)-(d) Field potentials resulting at axon (a, b) and soma (c, d) from axonal (a,c) and somatic (b, d) stimulation using $3 \mathrm{~ms}$ positive (blue) and negative (red) steps of about $200 \mu \mathrm{V}$ and a positive step of $6 \mathrm{~ms}$ (green). 
The solid lines and coloured bands represent mean \pm sem. The stimulation intensity was not altered upon moving the simulating electrode between the axon and the soma; for a given stimulation intensity, larger voltage responses were generated at the soma. (e, f) Modulation of the firing rate elicited by the same stimuli (colour coding as (a)-(d)). A positive extracellular step produced an inhibition of firing of $20.5 \pm 2.7 \mathrm{~Hz}$; the negative step elicited an inverse response. The longer step revealed the transient nature of the inhibition ( $t=0$ at the start of the stimulation). (g) Linear regression showing the correlation between the firing modulation and the amplitude of the extracellular voltage at the axon, irrespective of the site of stimulation: axon (filled circles; their linear regression is the black line with $95 \%$ confidence intervals in grey) or soma (open circles). (h, i) The mean extracellular field from Fig. $\mathbf{3} \mathbf{b}(t=0$ is the peak of the basket cell somatic action potential) was scaled to an amplitude of $298 \mu \mathrm{V}$ and applied near the axon (h); the resulting biphasic modulation of Purkinje cell firing is shown in (i) (green) and compared to the average response from Fig. 11 (red, same scale as green trace, scaled to the replay amplitude in blue).

\section{Figure 6: Opposing direct excitation}

Action potentials elicited by stimulation of parallel fibres in the molecular layer were recorded simultaneously in a basket cell and a Purkinje cell. Individual Purkinje (a) and basket (b) cell response histograms (grey) and averages (black). (Dashed line: $20 \%$ onset in the basket cell.) (c), The average modulations from Fig. $\mathbf{1 j}, \mathbf{n}$ were convolved with the probability density function of basket cell spike times (b) to obtain the single basket cell modulation of Purkinje cell firing via ephaptic and chemical mechanisms together (light grey) or via chemical transmission alone (dark grey). (d), Numerical prediction of the additive basket cell effect on the Purkinje cell during parallel fibre input. We added 10 times the average stimulated chemical (dark grey) or chemical and pinceau (light grey) effects (c) to the average Purkinje cell response (a). Inputs with the pinceau component would be more effective at preventing excitation of the Purkinje cell. At $1.6 \mathrm{~ms}$, the chemical inhibition briefly saturated firing rate at zero and the subsequent rate estimates are unreliable (dashed lines). 


\section{Methods}

\section{Slice preparation}

Animal experimentation methods complied with French and European regulations. Cerebellar slices were prepared from adult C57BL/6 female mice ( $>8$ weeks, Janvier or Charles River) by one of two methods. For most of the experiments, mice were anæsthetised with isoflurane (Nicholas Piramal India Ltd.) and killed by decapitation. The cerebellum was rapidly dissected into a cold solution containing the following (in $\mathrm{mM})^{51}$ : $130 \mathrm{~K}$-gluconate, $15 \mathrm{KCl}, 0.05$ EGTA, $20 \mathrm{HEPES}$, and 25 glucose, with $\mathrm{pH}$ adjusted to 7.4 by $\mathrm{NaOH}$, bubbled with $95 \% \mathrm{O}_{2} / 5 \% \mathrm{CO}_{2}$ and supplemented with $50 \mu \mathrm{M}$ DAPV. Sagittal slices $(360 \mu \mathrm{m})$ were cut in the same solution, using a Campden Instruments $7000 \mathrm{smz}$ slicer and stored at $32{ }^{\circ} \mathrm{C}$ in standard extracellular saline (bicarbonate-buffered solution; BBS), containing (in $\mathrm{mM}$ ): $135 \mathrm{NaCl}$, $26 \mathrm{NaHCO}_{3}, 3 \mathrm{KCl}, 1.25 \mathrm{NaH}_{2} \mathrm{PO}_{4}, 2 \mathrm{CaCl}_{2}, 1 \mathrm{MgCl}_{2}$ and $25 \mathrm{D}$-glucose, bubbled with $95 \% \mathrm{O}_{2} / 5 \% \mathrm{CO}_{2}$. Alternatively, for some cells of Figs. 1 and 5, mice were anæsthetised by ketamine/xylazine $(75 / 10 \mathrm{mg} / \mathrm{kg})$ i.p. The thorax was opened and transcardiac perfusion established using a hypodermic needle in the left ventricle and opening the right atrium. $\sim 10 \mathrm{ml}$ of $\mathrm{NaCl}$ - and sucrose-based solutions were successively perfused. The $\mathrm{NaCl}$ solution contained (in mM): $115 \mathrm{NaCl}, 26 \mathrm{NaHCO}_{3}, 3 \mathrm{KCl}, 0.8 \mathrm{CaCl}_{2}, 8$ $\mathrm{MgCl}_{2}, 1.25 \mathrm{NaH}_{2} \mathrm{PO}_{4}, 25$ glucose, 1 lidocaine, 1 ketamine. The sucrose solution contained 230 sucrose instead of $115 \mathrm{NaCl}$. Slices were cut with the same slicer in sucrose solution supplemented with $50 \mu \mathrm{M}$ D-APV.

\section{Recordings}

Recordings were performed at $32^{\circ} \mathrm{C}$ in BBS under a BX51WI microscope (Olympus) equipped with a CoolSNAP EZ camera (Photometrics) controlled using microManager ${ }^{52}$ and Image ${ }^{53}$. Whole-cell current-clamp recordings were obtained using a Multiclamp 700B (Molecular Devices) with bridge balance and capacitance neutralisation.

Capacitive coupling of the action potential from the basket cell electrode to any intracellular electrode used to record from the Purkinje cell could introduce spurious signals and perturb its firing. We therefore usually monitored Purkinje cell firing extracellularly, using a home-made amplifier implementing a high-gain differential headstage, referenced to the bath, to minimise interfering signals. The non-immersed portion of the electrodes were covered in a grounded shield. To reduce the risk of coupling between the recording electrodes that could arise from the voltage drop across the refer- 
ence resistance, the bath potential was clamped using a custom-built virtual ground. Interference from the action potential in the basket cell electrode to the extracellular recording was thus attenuated to about $1 \mu \mathrm{V}$ (Fig. 2c trace 1). Data were digitised using an NI-6229 analog to digital converter (National Instruments). Experiments were controlled using the WinWCP freeware (John Dempster, Strathclyde Electrophysiology Software). The composition of the pipette solution was (in mM): 0.4 Na-GTP, 0.5 L-(-)Malic acid, 0.008 Oxaloacetic acid, $0.18 \alpha$-Ketoglutaric acid, 0.2 Pyridoxal 5'-phosphate hydrate, 5 L-Alanine, 0.15 Pyruvic acid, 15 L-Glutamine, 4 LAsparagine, 1 L-Glutathione reduced, 10 Hepes, $4 \mathrm{KCl}, 10 \mathrm{GABA}, 2.1 \mathrm{Mg}$ ATP, 1.4 Na-ATP, 5 Phospho-creatine-K ${ }_{2}$, $0.5 \mathrm{~K}_{3}$-Citrate, $120 \mathrm{~K}$-Gluconate, 0.1 EGTA, $2.2 \mathrm{~K}_{2}$-Phosphate, $0.05 \mathrm{CaCl}_{2}$ and was supplemented with either $0.75 \mathrm{mM}$ Alexa 568-hydrazide or $10 \mathrm{mM}$ EZ-link amine-PEG ${ }_{3}$-biotin (Thermo Scientific) and $20 \mu \mathrm{M}$ Alexa 488-hydrazide. We purchased: chemicals from Sigma; drugs from Ascent, Tocris, Alomone ( $\alpha$-DTX), Latoxan $(\alpha$-DTX), and Sigma (TTX); fluorophores from Life Technologies.

Potentials are reported without correction for junction potentials.

Extracellular stimulation with an isolated stimulator (model 2100, A-M Systems) or a home-built non-isolated stimulator (used in conjunction with the virtual ground circuit) employed patch pipettes (resistance 1-10 M $\Omega$ ) filled with a HEPES buffer solution containing (in $\mathrm{mM}$ ) $141 \mathrm{NaCl}, 2.5 \mathrm{KCl}$, $1.25 \mathrm{NaH}_{2} \mathrm{PO}_{4}, 10 \mathrm{HEPES}, 1.6 \mathrm{CaCl}_{2}$ and $1.5 \mathrm{MgCl}_{2}$ and 25 glucose. The home-built voltage-mode stimulator could be driven with an analog command.

In experiments applying extracellular voltage changes (Fig. 5), a stimulator in voltage mode was connected to a saline-filled patch electrode. Measurements at the tip of this electrode with low-impedance patch electrodes established that the voltage change in the extracellular space faithfully followed the waveform of the command voltage, with little filtering. The command was, however, strongly attenuated by the voltage divider formed by the resistance of the stimulating electrode and that of the bath solution. We therefore used recording electrodes placed at the tip of the stimulating electrode to adjust the final amplitude. During the experimental recordings, these smaller-tipped electrodes were also shielded, the extra capacitance resulting in additional filtering, typically $\tau=2.6 \mathrm{~ms}$. This was taken into account in calculating the amplitude of final voltage change. (The command was R-C filtered to achieve the same waveform, and the resulting amplitude ratio determined under these conditions.) We show the unfiltered, attenuated voltage waveforms in the figures; these represent the most accurate estimate of the applied voltage. 
In experiments of Fig. 6, stimulation electrodes were placed at least $200 \mu \mathrm{m}$ below the slice surface to avoid any direct stimulation of the neurones.

\section{Pinceau identification}

Identification of pinceaux made use of epifluorescence images of the basket cell labelled via the recording pipette and transmitted light images of the slice. A provisional classification was performed online to aid targeting of recordings. A more accurate offline classification was performed using the same data sources but benefited from images with better filling of the basket cell axon because they were obtained at the end of the experiment. The classification of pinceau connections was based solely on these images and took no account of the associated electrophysiology. A pinceau was identified if the basket cell axon reached the quadrant of the Purkinje cell facing the granule cell layer, travelled into the granule cell layer and displayed an expansion at that location. These criteria were chosen because basket cell axons only extend into the granule cell layer within the pinceau, which is an extensive structure covering much of the lower surface of every Purkinje cell body.

A post hoc evaluation of the classification can be performed by assuming that gabazine-resistant responses Fig. 1 reflect the true presence of a pinceau connection. By this measure the estimate of the false-positive rate of our classification was $2 / 14=14 \%$, while that for the false-negative rate would be $1 / 9=11 \%$. These rates did not prevent the demonstration of a strong and significant correlation between the presence of a pinceau and the ephaptic inhibition.

For the experiments of Fig. 3, after initial targeting using epifluorescence images, the pipette position was adjusted until an extracellular positivity could be recorded.

\section{Immunohistochemistry}

A small number of slices were fixed (4 slices, corresponding to 7 recordings, 4 from the 'pinceaux' group, 3 from the control group), labelled for a marker of the pinceau and examined using confocal microscopy. An example image from these experiments is shown in Fig. 1c. After recording, an outside-out patch was established and slices were perfused with saline containing (in mM): 230 sucrose, $26 \mathrm{NaHCO}_{3}, 3 \mathrm{KCl}, 1.25 \mathrm{NaH}_{2} \mathrm{PO}_{4}, 0.8$ $\mathrm{CaCl}_{2}, 8 \mathrm{MgCl}_{2}$ and 25 D-glucose, bubbled with $95 \% \mathrm{CO}_{2} / 5 \% \mathrm{O}_{2}$ for $5 \mathrm{~min}$. 
Slices were fixed in the same solution in $4 \%$ paraformaldehyde, washed in PBS after $30 \mathrm{~min}$, embedded in porcine gelatin type $\mathrm{A}$ and resliced on a vibratome (Leica VT1000S). Free-floating sections (40 to $70 \mu \mathrm{m})$ were incubated in citrate buffer $(10 \mathrm{mM}$ Na-citrate, $\mathrm{pH} 6)$, heated $5 \mathrm{~min}$ in microwave oven at $1 \mathrm{~kW}$ for decloaking and put on ice for $15 \mathrm{~min}$. Sections were permeabilised and blocked in (in $\mathrm{mM}$ ) 0.1 Tris-HCl pH 7.5, 0.15 NaCl, $0.5 \%$ blocking reagent (PerkinElmer, reference FP1020) with 1\% Triton for one hour and washed thoroughly in TNT solution containing $0.05 \%$ Tween20, Tris $100 \mathrm{mM}, \mathrm{NaCl} 150 \mathrm{mM}$. Anti-NfP (phosphorylated neurofilament) monoclonal antibody (SMI-31P; Sternbach) was applied to the sections at $1 / 200$ overnight at $4{ }^{\circ} \mathrm{C}$. Finally, sections were incubated overnight in Alexa 633-conjugated secondary antibody and Alexa 488-conjugated streptavidin (1/200), washed in TNT and mounted in Prolong Gold (Life Technologies). Images were acquired on a Leica TCS SP5 confocal microscope (Leica Microsystems).

\section{Data analysis}

The detection of Purkinje cell extracellular action potentials could potentially be affected by the extracellular field induced by the basket cell action potential (Fig. 2). We therefore constructed the average basket cell action potential field by subtracting average traces where the Purkinje cell was not active close to the time of the basket cell action potential (Supplementary Fig. 3a) from average traces where neither the Purkinje cell or the basket cell were active (Supplementary Fig. 3b,c), giving a signal much like that in Fig. 2d. This field was subtracted from raw traces (Figs. 1e and Supplementary Fig. 3d) before high-pass filtering ( $5 \mathrm{~ms}$ box filter) and detection of spikes with a simple threshold. We note that the biphasic pinceau effect on firing rate (Fig. 11) is of a form incompatible with that expected from a simple detection artefact, which would have a shape similar to the extracellular signal (Fig. 2d). This further argues against interference of the field in spike detection.

Typical Purkinje cell spikes displayed a small but long-lasting overshoot (see average in Supplementary Fig. 4). The exclusion of spikes from the central window in Supplementary Fig. 3 and the decay of the overshoots from non-excluded spikes produced the rather strange alternating variations of the means in Supplementary Fig. 3. Note that these were in any case perfectly subtracted at a later stage of the analysis (Supplementary Fig. 3c).

Electrophysiological data were analysed in Python using custom soft- 
ware relying on the numpy and scipy packages ${ }^{54}$. Smooth correlograms and spike distributions were obtained by convolving a Gaussian kernel with spike times. For Fig. 1 we used $\sigma=0.33 \mathrm{~ms}$ and at least 4,000 spikes; for Fig. 6, $\sigma=0.15 \mathrm{~ms}$ and at least 300 stimuli. Field recordings are averages of at least 900 traces. For Fig. 5, at least 3,000 repetitions of each extracellular stimuli were used. Unless otherwise stated, latencies are with respect to the peak of the basket cell action potential. Data are reported as mean \pm sem. Non-parametric tests were preferred and performed in $G N U$ $R^{55}$. Two-tailed tests were systematically used. The correlations of extracellular voltage changes with firing modulation in Fig. $\mathbf{5}$ were tested using a linear mixed model ( $n l m e$ package in $G N U R$ ).

Image preparation was carried out using FIJI/ImageJ software ${ }^{53}$.

\section{Modelling}

The equivalent electrical circuit used to model the pinceau is shown in Fig. 4a. Many of the parameters were estimated from geometrical information drawn from the anatomical literature ${ }^{4}$. The action potential waveform recorded at the basket cell soma propagated with little decrement from the basket $\left(V_{I}\right)$ to the pinceau $\left(V_{B A}\right)$ through an axonal axial resistance $\left(R_{I}=13 \mathrm{M} \Omega\right)$. The portion of basket cell axon in the pinceau had capacitance $C_{B A}=1 \mathrm{pF}$, based ${ }^{4}$ upon 5 collaterals with a length of $7 \mu \mathrm{m}$ and a radius of $0.5 \mu \mathrm{m}$. The Purkinje cell soma and dendrites were modelled as two capacitors ${ }^{56}\left(C_{S}=10 \mathrm{pF}, C_{D}=750 \mathrm{pF}\right)$ joined by $R_{J}=5 \mathrm{M} \Omega$, and the axon as a capacitor $C_{P A}=0.25 \mathrm{pF}$ connected to the soma through resistance $R_{A S}=30 \mathrm{M} \Omega$ (assuming an axonal radius of $0.4 \mu \mathrm{m}$ and length of $10 \mu \mathrm{m})$. The Purkinje cell axonal, somatic and dendritic potentials were $V_{P A}, V_{S}$ and $V_{D}$. The Purkinje cell somatic extracellular voltage, $V_{S E}$, was grounded except in Supplementary Fig. 2, when an extracellular spike was imposed upon it. The presence of specialised septate junctions in the pinceau $^{3}$ was assumed to create an intra-pinceau extracellular space $V_{P}$ isolated by a resistance $R_{P}=300 \mathrm{k} \Omega$ with a smaller resistance $R_{E}=79.6 \mathrm{k} \Omega$ in series accounting for the recorded extracellular waveform $\left(V_{E}\right)$ with respect to the bath potential (ground). The latter was approximated as $R=\frac{1}{4 \pi \sigma r}$, the resistance between a sphere of radius $r=2.5 \mu \mathrm{m}$ and a ground at infinity in a conductive medium ${ }^{57}$ of resistivity $\sigma=0.4 \mathrm{Sm}^{-1}$. A voltage-dependent potassium conductance $\overline{G_{K}}=5.8 \mathrm{nS}$ was implemented in the pinceau, based upon the characterisation of those in the basket ${ }^{28,29}$, assuming a $Q_{10}$ of 3 . 
The system was described by the following system of equations:

$$
\begin{aligned}
\frac{\mathrm{d} V_{D}}{\mathrm{~d} t} & =\frac{V_{S}-V_{D}}{C_{D} R_{J}} \\
\frac{\mathrm{d} V_{S}}{\mathrm{~d} t} & =\frac{1}{C_{S}}\left(\frac{V_{P A}-V_{S}}{R_{A S}}-\frac{V_{S}-V_{D}}{R_{J}}\right)+\frac{\mathrm{d} V_{S E}}{\mathrm{~d} t} \\
\frac{\mathrm{d} V_{P A}}{\mathrm{~d} t} & =\frac{\mathrm{d} V_{P}}{\mathrm{~d} t}-\frac{V_{P A}-V_{S}}{R_{A S} C_{P A}} \\
\frac{\mathrm{d} V_{P}}{\mathrm{~d} t} & =F\left(\frac{\mathrm{d} V_{I}}{\mathrm{~d} t}+\frac{R_{I}}{R_{A S}} \frac{\mathrm{d} V_{S}}{\mathrm{~d} t}+\frac{\left(V_{P A}-V_{S}\right)}{R_{A S} C_{e q}}-\frac{V_{P}}{R_{L} C_{B A}}+\frac{I_{K}}{C_{B A}}\right)
\end{aligned}
$$

where:

$$
\begin{aligned}
R_{L} & =R_{E}+R_{P} \\
F & =\frac{R_{L} R_{A S}}{R_{A S} R_{I}+R_{A S} R_{L}+R_{L} R_{I}} \\
\frac{1}{C_{e q}} & =\frac{R_{I}}{R_{A S} C_{P A}}-\frac{1}{C_{B A}} \\
I_{K} & =\overline{G_{K}}\left(V_{B A}-V_{P}-E_{K}\right) n^{4} \\
V_{B A} & =V_{I}-R_{I}\left(\frac{V_{P A}-V_{S}}{R_{A S}}+\frac{V_{P}}{R_{L}}\right) \\
V_{E} & =V_{P} \frac{R_{E}}{R_{L}}
\end{aligned}
$$

Applying the formalism of Hodgkin and Huxley ${ }^{58,59}$ to currents recorded from basket cell terminals (see Figs. $1 \mathrm{C}$ and $2 \mathrm{C}$ of $\operatorname{ref}^{28}$ ), the potassium conductance was described by:

$$
\begin{aligned}
\frac{\mathrm{d} n}{\mathrm{~d} t} & =\frac{m\left(V_{B A}-V_{P}\right)-n}{\tau\left(V_{B A}-V_{P}\right)} \\
m(V) & =\frac{1}{1+\exp \left(-\frac{V+73.95}{26.99}\right)} \\
\tau(V) & =0.19\left(\frac{1}{\exp \left(\frac{V+33.1}{19.4}\right)}+0.5\right)
\end{aligned}
$$

When included, firing in the Purkinje cell was implemented with a simple threshold on the axonal membrane potential of the Purkinje cell $\left(V_{P A}-V_{P}\right)$, with a uniform reset $(\Delta=-15 \mathrm{mV})$ of $V_{P A}, V_{S}$ and $V_{D}$ and without a 
refractory period. A constant, uniform pacemaking current drove Purkinje cell firing at $50 \mathrm{~Hz}$.

These equations were integrated numerically using the integrate.odeint module from scipy. The model was adjusted to reproduce the overall form of the observed extracellular potential and modulation of Purkinje cell firing by varying the isolation resistance $\left(R_{P}\right)$ and peak potassium conductance $\left(\overline{G_{K}}\right)$. The effects of $0.5-1.5$ fold variations of the main parameters are illustrated in Supplementary Fig. 5. 


\section{References}

[1] Thach, W.T., Goodkin, H.P. \& Keating, J.G. Annu Rev Neurosci 15, 403-442 (1992).

[2] Ramón y Cajal, S. Histologie du système nerveux de l'homme et des vertébrés., volume Tome II. Paris: Maloine (1911).

[3] Sotelo, C. \& Llinás, R. J Cell Biol 53, 271-289 (1972).

[4] Bobik, M., Ellisman, M.H., Rudy, B. \& Martone, M.E. Brain Res 1026, 168-178 (2004).

[5] Iwakura, A., Uchigashima, M., Miyazaki, T., Yamasaki, M. \& Watanabe, M. The Journal of Neuroscience 32, 9438-9448 (2012).

[6] Furukawa, T. \& Furshpan, E.J. Journal of Neurophysiology 26, 140-176 (1963).

[7] Furshpan, E.J. \& Furukawa, T. Journal of Neurophysiology 25, 732-771 (1962).

[8] Palay, S.L. In RNA and brain function, memory and learning; proceedings of the second conference. Univ. of California Press, Berkeley (1964).

[9] Fox, C.A., Hillman, D.E., Siegesmund, K.A. \& Dutta, C.R. In Clement A. Fox and Ray S. Snider, ed., Progress in Brain Research, volume Volume 25, 174-225. Elsevier (1967).

[10] Arvanitaki, A. Journal of Neurophysiology 5, 89-108 (1942).

[11] Anastassiou, C.A., Perin, R., Markram, H. \& Koch, C. Nat Neurosci 14, 217-223 (2011).

[12] Su, C.Y., Menuz, K., Reisert, J. \& Carlson, J.R. Nature 492, 66-71 (2012).

[13] Korn, H. \& Axelrad, H. Proc Natl Acad Sci U S A 77, 6244-6247 (1980).

[14] Blot, A. \& Barbour, B. bioRxiv doi: 10.1101/001123 (2013).

[15] Silver, I.A. \& Erecińska, M. J Gen Physiol 95, 837-866 (1990). 
[16] Pouzat, C. \& Hestrin, S. J Neurosci 17, 9104-9112 (1997).

[17] de Solages, C. et al. Neuron 58, 775-788 (2008).

[18] Palay, S.L. \& Chan-Palay, V. Cerebellar cortex: cytology and organization. Springer (1974).

[19] Palkovits, M., Magyar, P. \& Szentágothai, J. Brain Research 34, 1 18 (1971).

[20] Buttermore, E.D. et al. J Neurosci 32, 4724-4742 (2012).

[21] Bishop, G.A. Anat Embryol (Berl) 188, 287-297 (1993).

[22] Foust, A., Popovic, M., Zecevic, D. \& McCormick, D.A. J Neurosci 30, 6891-6902 (2010).

[23] Faber, D.S. \& Korn, H. Science 179, 577-578 (1973).

[24] Korn, H. \& Faber, D.S. Science 194, 1166-1169 (1976).

[25] Rhodes, K.J. et al. J Neurosci 17, 8246-8258 (1997).

[26] Laube, G. et al. Brain Res Mol Brain Res 42, 51-61 (1996).

[27] Rhodes, K.J. et al. J Neurosci 16, 4846-4860 (1996).

[28] Southan, A.P. \& Robertson, B. J Neurosci 20, 114-122 (2000).

[29] Southan, A.P. \& Robertson, B. J Neurosci 18, 948-955 (1998).

[30] Harvey, A.L. Toxicon 39, 15 - 26 (2001).

[31] Brigant, J.L. \& Mallart, A. J Physiol 333, 619-636 (1982).

[32] Roth, A. \& Häusser, M. The Journal of Physiology 535, 445-472 (2001).

[33] Lorincz, A. \& Nusser, Z. J Neurosci 28, 14329-14340 (2008).

[34] Jaeger, D. J Comput Neurosci 14, 311-327 (2003).

[35] Ostojic, S., Brunel, N. \& Hakim, V. J Neurosci 29, 10234-10253 (2009).

[36] Eccles, J.C., Ito, M. \& Szentágothai, J. The cerebellum as a neuronal machine. Berlin, Heidelberg, New York: Springer-Verlag (1967). 
[37] Mann-Metzer, P. \& Yarom, Y. Prog Brain Res 124, 115-122 (2000).

[38] Mann-Metzer, P. \& Yarom, Y. J Neurosci 19, 3298-3306 (1999).

[39] Brunel, N. \& Hakim, V. Neural Comput 11, 1621-1671 (1999).

[40] Kondo, S. \& Marty, A. J Physiol 509 ( Pt 1), 221-232 (1998).

[41] Person, A.L. \& Raman, I.M. Nature 481, 502-505 (2012).

[42] Jörntell, H. \& Ekerot, C.F. Neuron 34, 797-806 (2002).

[43] Mittmann, W. \& Häusser, M. J Neurosci 27, 5559-5570 (2007).

[44] Chadderton, P., Margrie, T.W. \& Häusser, M. Nature 428, 856-860 (2004).

[45] Jörntell, H. \& Ekerot, C.F. J Neurosci 26, 11786-11797 (2006).

[46] Ito, M., Yoshida, M., Obata, K., Kawai, N. \& Udo, M. Exp Brain Res 10, 64-80 (1970).

[47] Isope, P. \& Barbour, B. J Neurosci 22, 9668-9678 (2002).

[48] Brunel, N., Hakim, V., Isope, P., Nadal, J.P. \& Barbour, B. Neuron 43, 745-757 (2004).

[49] Barbour, B., Brunel, N., Hakim, V. \& Nadal, J.P. Trends Neurosci 30, 622-629 (2007).

[50] Howard, A., Tamas, G. \& Soltesz, I. Trends Neurosci 28, 310-316 (2005).

[51] Dugué, G.P. et al. Neuron 61, 126-139 (2009).

[52] Edelstein, A., Amodaj, N., Hoover, K., Vale, R. \& Stuurman, N. Computer Control of Microscopes Using $\mu$ Manager. John Wiley and Sons, Inc. (2010).

[53] Abramoff, M.D., Magelhaes, P.J. \& Ram, S.J. Biophotonics Int 11, $36-42(2004)$.

[54] Jones, E., Oliphant, T., Peterson, P. et al. SciPy: Open source scientific tools for Python (2001). 
[55] R Development Core Team. R: A Language and Environment for Statistical Computing. R Foundation for Statistical Computing, Vienna, Austria (2011).

[56] Llano, I., Marty, A., Armstrong, C.M. \& Konnerth, A. J Physiol 434, 183-213 (1991).

[57] Okada, Y.C., Huang, J.C., Rice, M.E., Tranchina, D. \& Nicholson, C. J Neurophysiol 72, 742-753 (1994).

[58] Hodgkin, A.L. \& Huxley, A.F. The Journal of Physiology 117, 500-544 (1952).

[59] Huguenard, J.R. \& McCormick, D.A. Journal of Neurophysiology 68, 1373-1383 (1992). 


\section{Author contributions}

A.B. performed all experiments and analyses. B.B. designed and built the custom electronics. Together they designed the experiments and analyses, interpreted the results, developed the model and wrote the manuscript. 

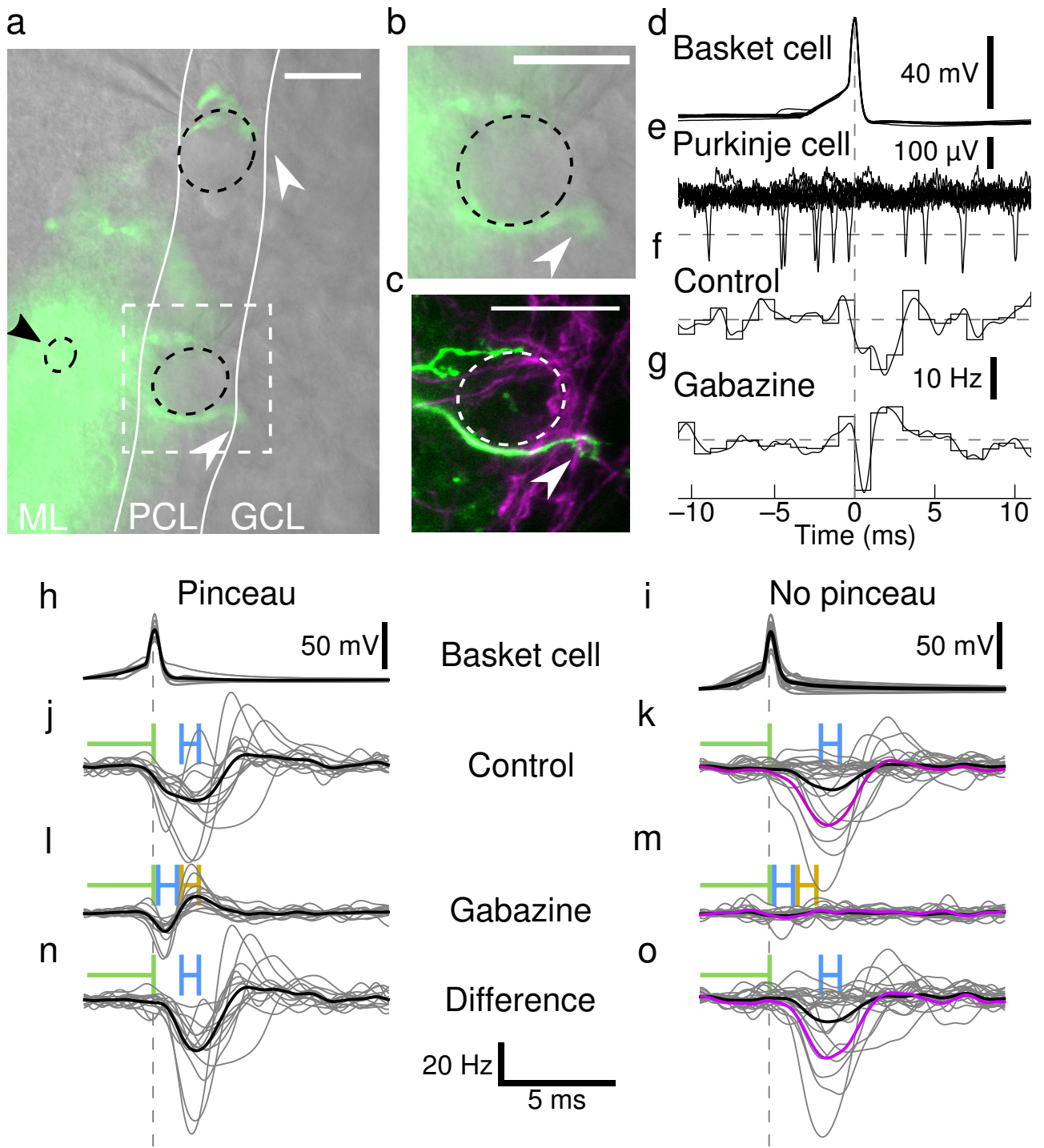

Figure 1: Non-synaptic inhibition of Purkinje cells 

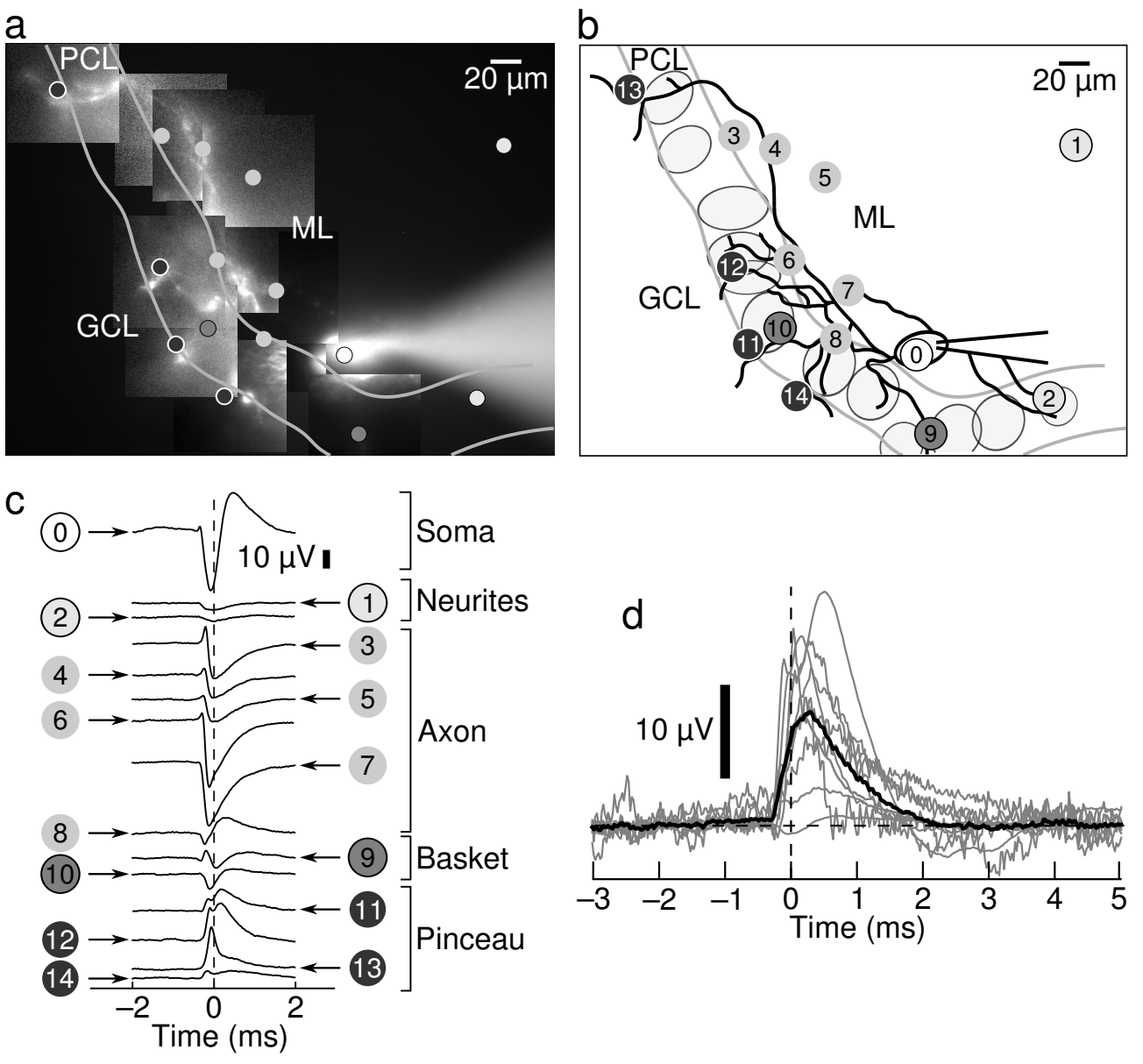

Figure 2: Extracellular voltage field at the pinceau 

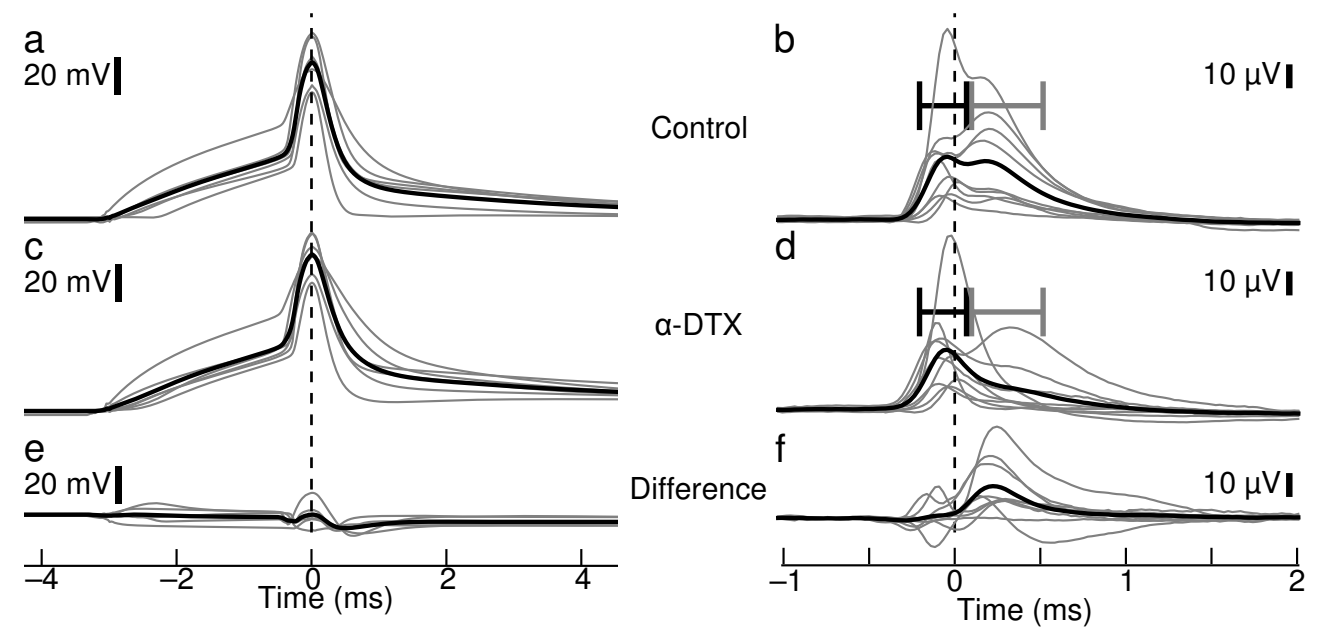

Figure 3: Two components of the pinceau field 

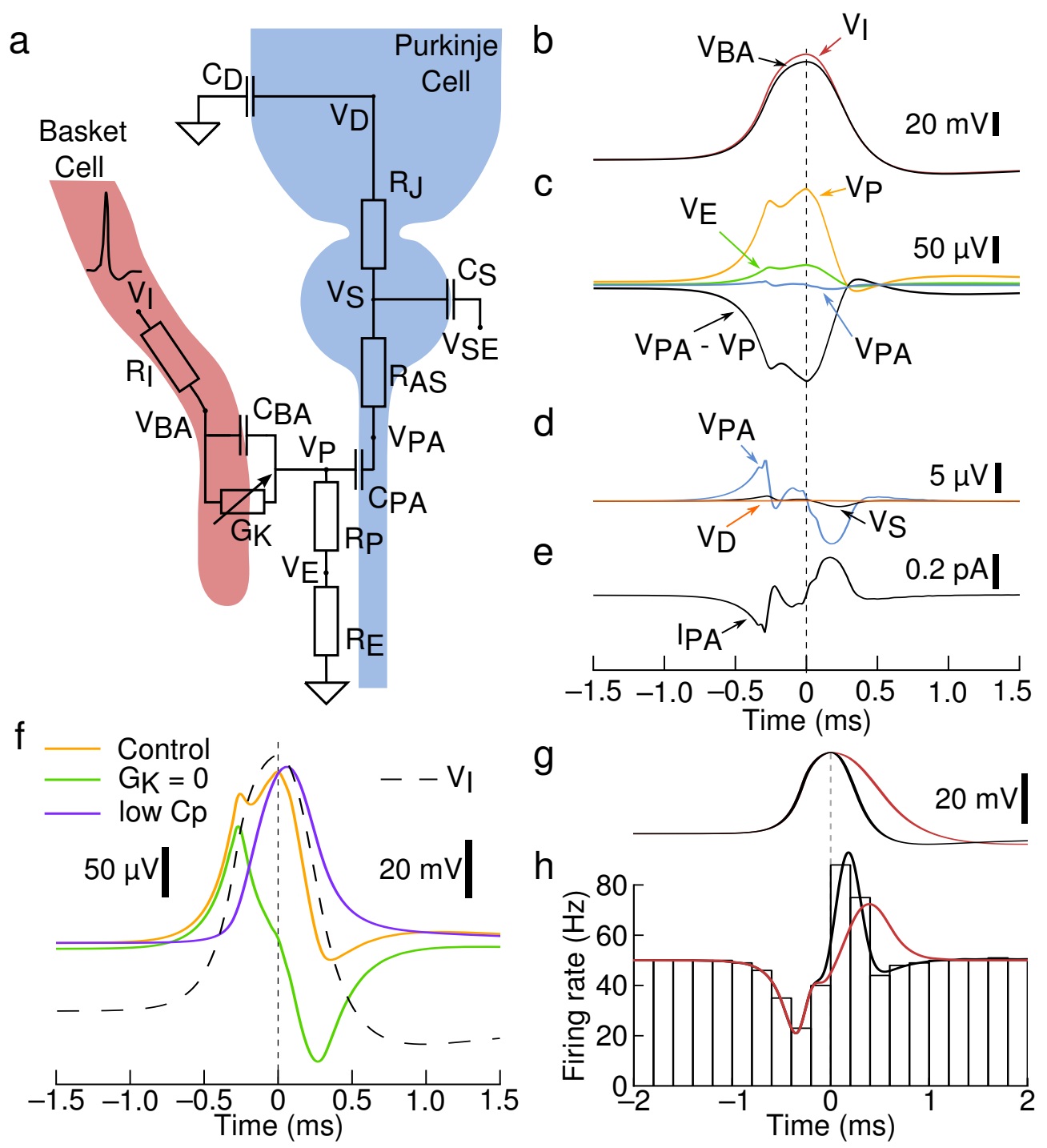

Figure 4: Pinceau model 

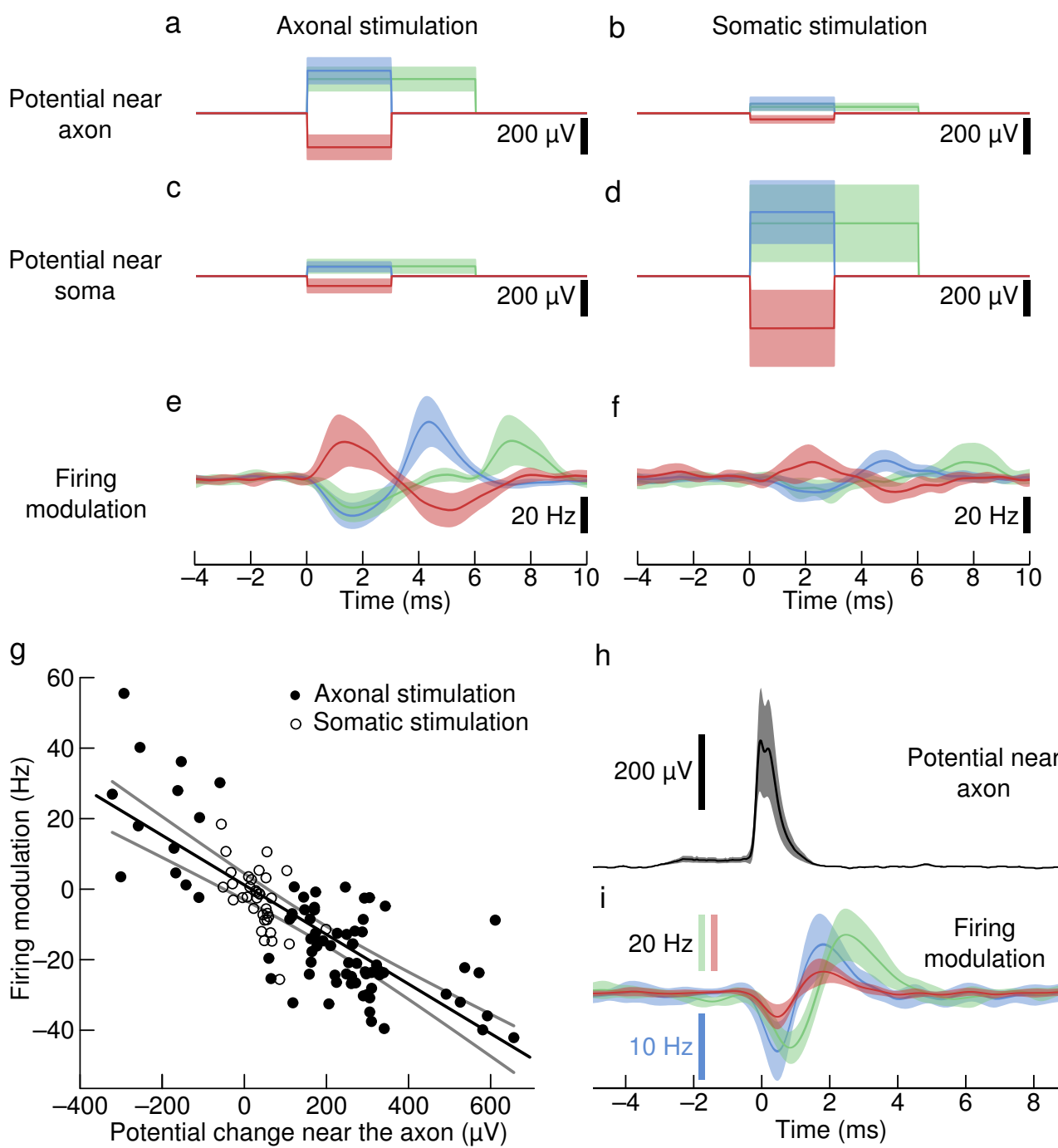

h

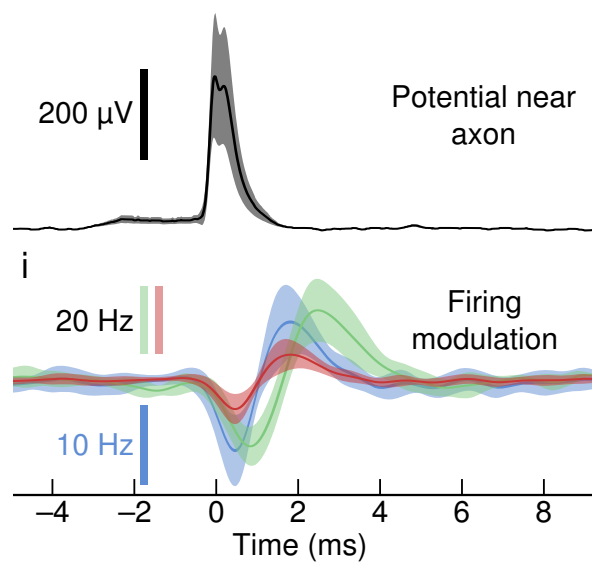

Figure 5: Extracellular voltage clamp 

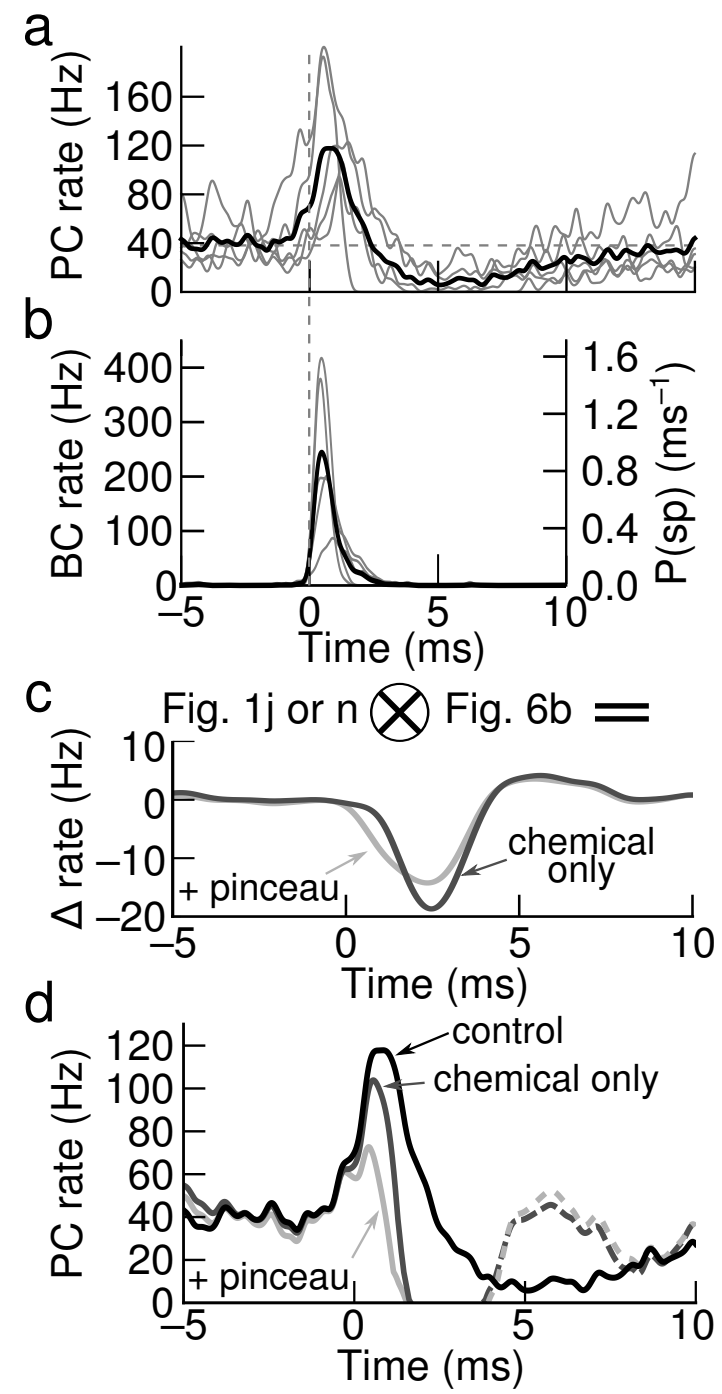

Figure 6: Opposing direct excitation 


\title{
Ultra-rapid axon-axon ephaptic inhibition of cerebellar Purkinje cells by the pinceau: Supplementary information
}

\author{
Antonin Blot \& Boris Barbour \\ Ecole Normale Supérieure, IBENS, Paris, F-75005, France. \\ CNRS, UMR 8197, Paris, F-75005, France. \\ INSERM, U 1024, Paris, F-75005, France. \\ Correspondance: boris.barbour@ens.fr
}

December 6, 2013 
a

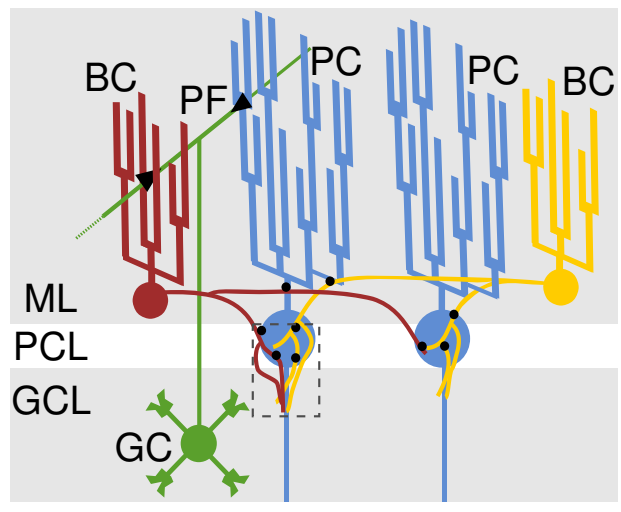

Excitatory synapse

- Inhibitory synapse b

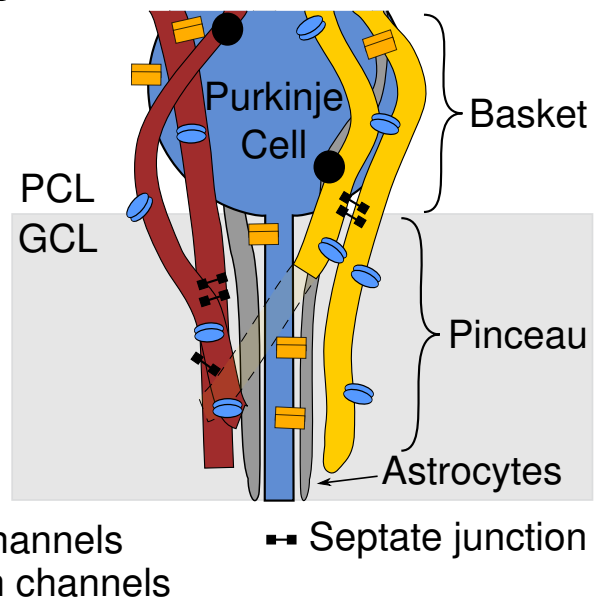

Supplementary Figure 1: The pinceau. (a), Diagram of Purkinje cells, basket cells and granule cells in the cerebellar cortex. (b), Organisation of the basket and pinceau. BC, basket cell; GC, granule cell; GCL, granule cell layer; ML, molecular layer; PF, parallel fibre; PC, Purkinje cell; PCL, Purkinje cell layer. 


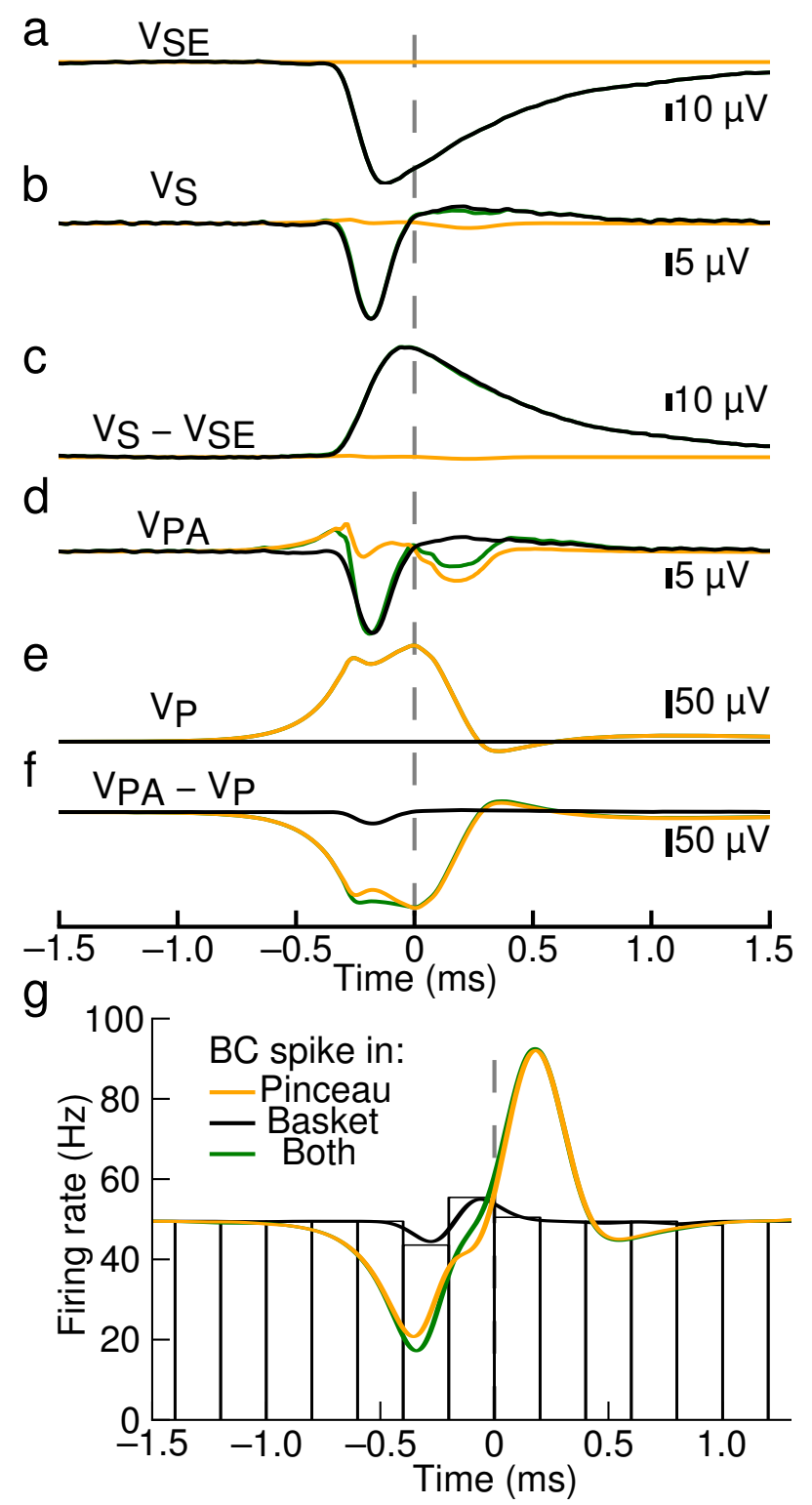

Supplementary Figure 2: Small effect of an action potential in the basket. The Purkinje cell soma is surrounded by the axons of basket cells (diagram in Supplementary Fig. 1). The propagation of the action potential of the interneurone in this perisomatic basket could itself affect the somatic voltage of Purkinje cell and thus its firing, though the control cells 
in Fig. 1i,k, $\mathbf{m}, \mathbf{o}$ suggest this action is weak, if present. To gain insight into this possible mechanism, we modelled changes of extracellular voltage at the soma (black) by changing $V_{S E}$ and compared the result to the effects of the pinceau already modelled (orange) and of action potentials in both compartments (green). Spike propagation in the basket can be active, because an extracellular negativity could be observed there (Fig. 2c, traces 9 and 10). To estimate an upper limit on the contribution of an action potential in the basket we set $V_{S E}$ to twice the recorded trace with the maximal negativity (Fig. 2c trace 7), thus assuming a spatially uniform negativity of $-70 \mu \mathrm{V}$ around the soma (a) (both the amplitude and uniformity of this signal cause overestimation of its effect). This change of extracellular potential capacitively hyperpolarises the Purkinje cell soma (b) by $20 \mu \mathrm{V}$. The somatic transmembrane potential is depolarised (c). The intracellular hyperpolarisation propagates to the axon $(\mathbf{d})$ with very little decrement. These changes do not affect the intra-pinceau potential (e), producing a net transmembrane hyperpolarisation of the Purkinje cell axon (f). However, even in this overestimate, the hyperpolarisation caused in the Purkinje cell axon by the basket is small compared to the pinceau effect and the firing of the Purkinje cell is only weakly modulated $(\mathbf{g})$. The basket-induced signals described above would render impossible the intracellular detection of the pinceau signal, which we showed in Fig. 4 would in any case be undetectably small. The only method able to demonstrate the pinceau effect on the Purkinje cell is therefore measurement of its effect on firing. 


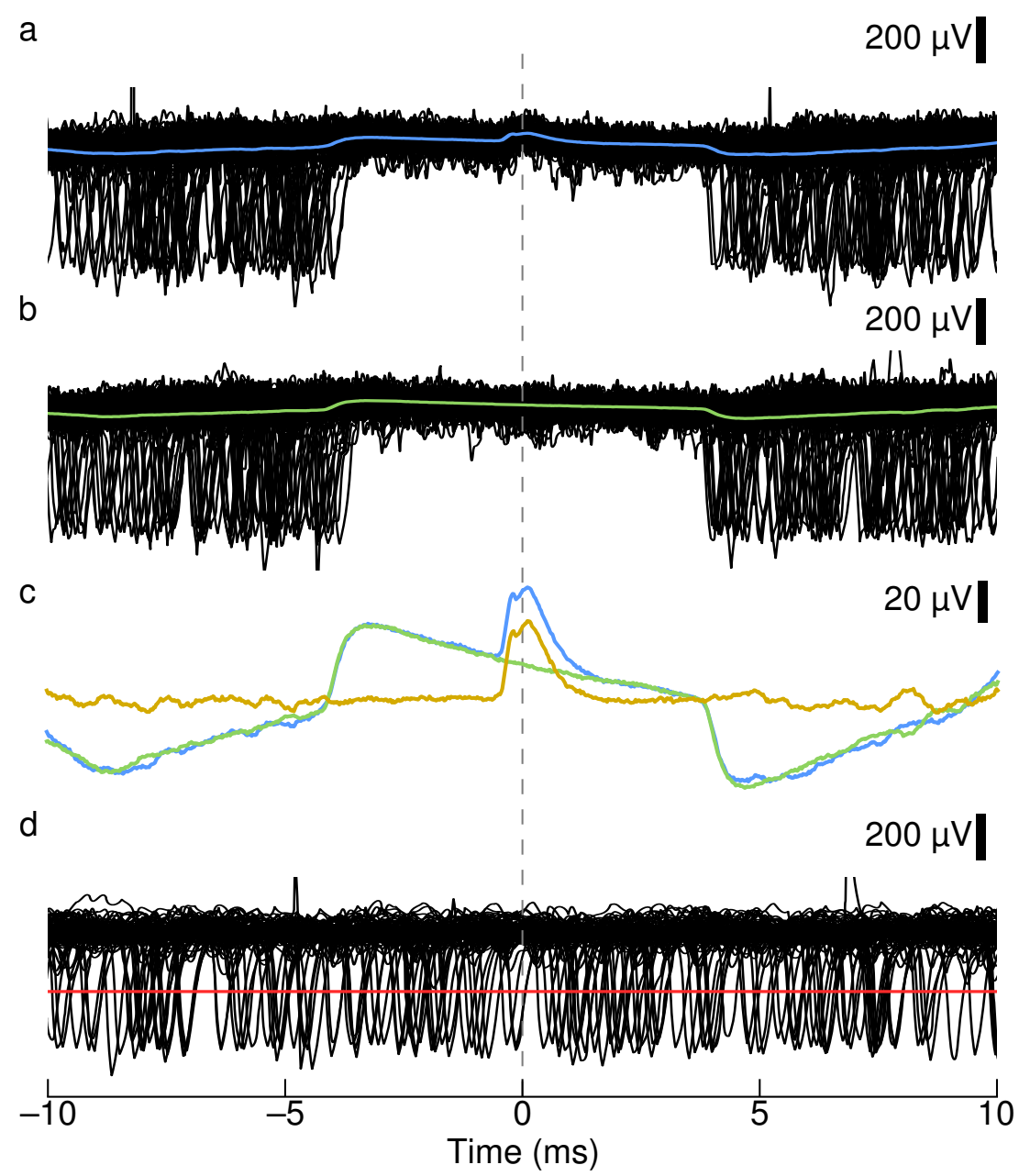

Supplementary Figure 3: Detection method. The extracellular field induced by the spikes of basket cells was computed by averaging recording periods (triggered on basket cell action potentials) that were devoid of Purkinje cell spikes (a), (c) (blue). We subtracted from this first trace an average of periods with no spike in either the Purkinje cell or the Basket cell (b), (c) (green). The resulting field (c) (yellow) was subtracted from every trace (d) and Purkinje cell spikes were then detected using a simple threshold (d) (red) on these snippets ( $\pm 20 \mathrm{~ms}$ around each basket cell spike) after baseline subtraction by a $5 \mathrm{~ms}$ high-pass box filter. 


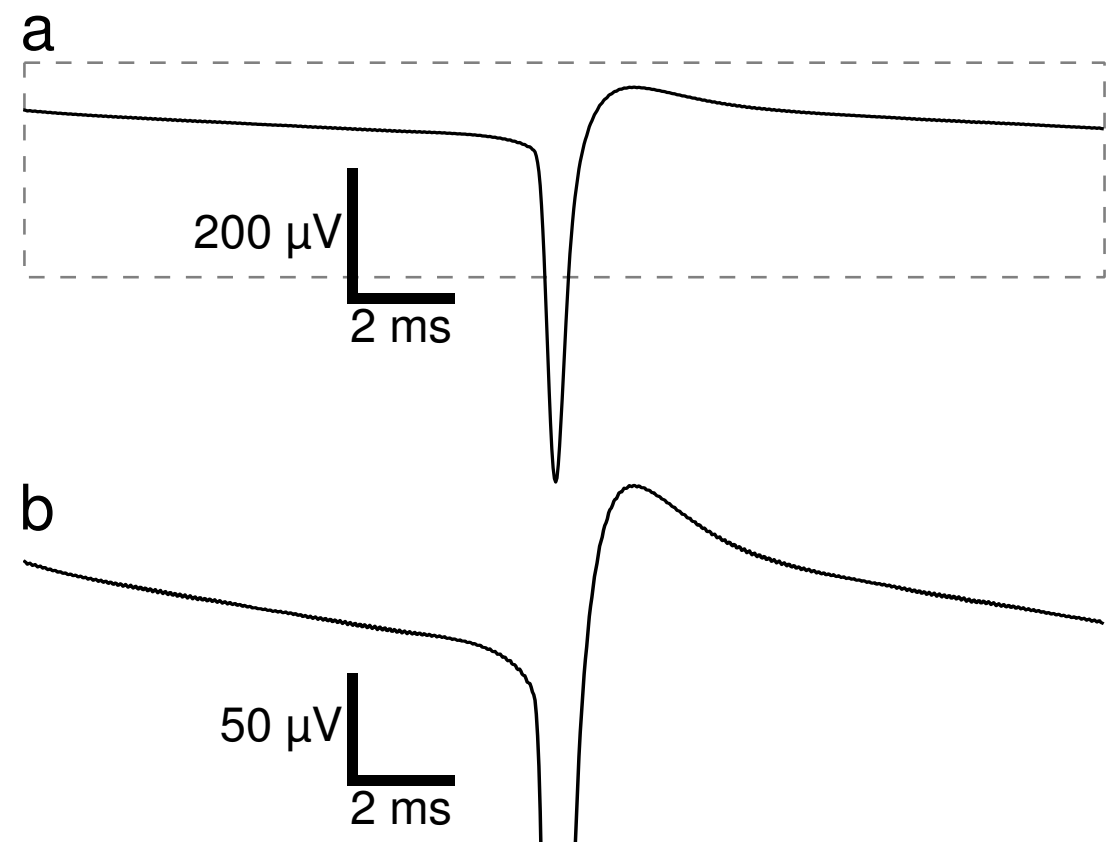

Supplementary Figure 4: Average spike waveform of Purkinje cell. (a) Average spike of the Purkinje cell in Supplementary Fig. 3. (b) Expanded view of the dashed box in (a). Purkinje cell spikes are followed by a long-lasting overshoot. The repetitive firing of the Purkinje (at $70 \mathrm{~Hz}$ ) explains the slope preceding the spike. Average of 137,672 spikes. 


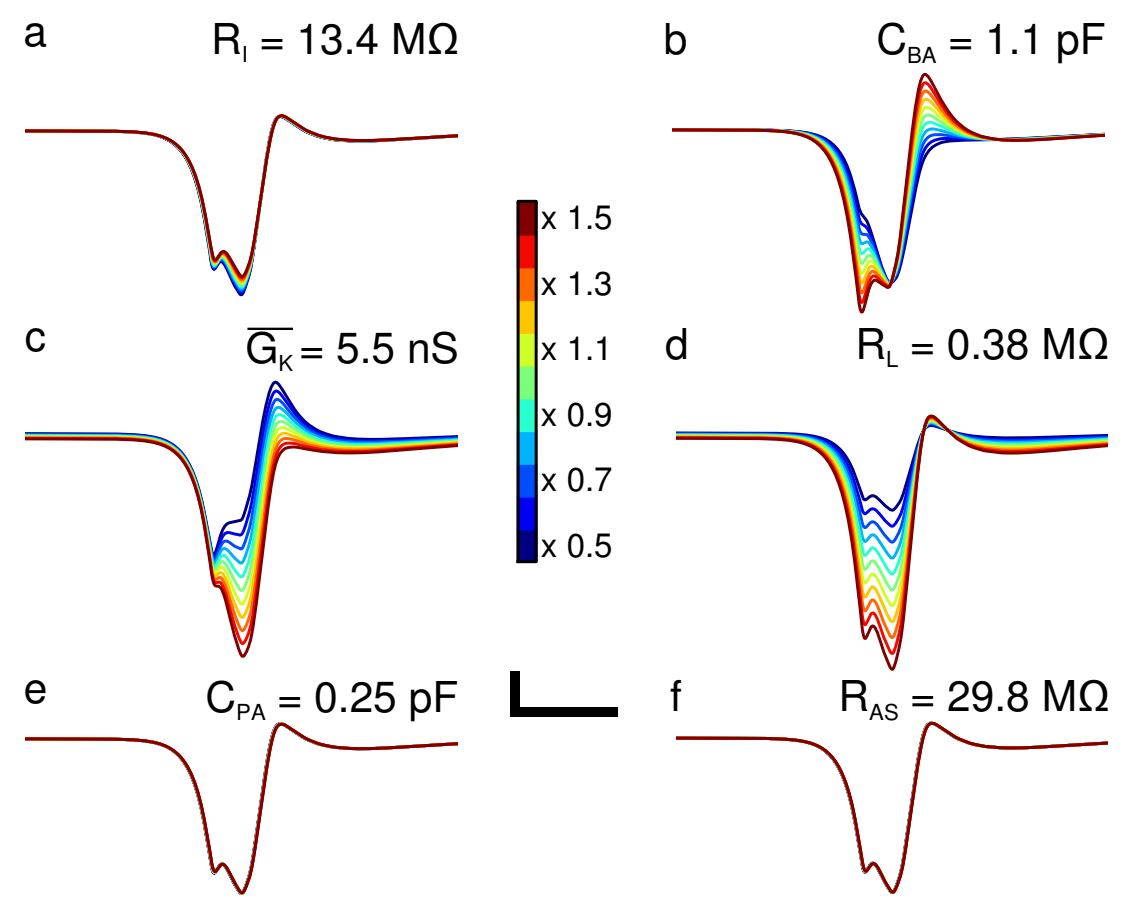

Supplementary Figure 5: Sensitivity analysis of the model. Effects of varying the principal parameters of the model (Fig. 4) on the membrane potential of the Purkinje cell axon $\left(V_{P A}-V_{P}\right)$. Changes of (a): $R_{I}$, (b): $C_{B A},(\mathbf{c}): \overline{G_{K}},(\mathbf{d}): R_{L},(\mathbf{e}): C_{P A},(\mathbf{f}): R_{A S}$. Colour map: multiplicative change of the value indicated in each panel and used in the paper (green curves). Scale bar: $50 \mu \mathrm{V}, 1 \mathrm{~ms}$. 